Bundesgesundheitsbl - Gesundheitsforsch Gesundheitsschutz 2008 · 51:1464-1482 DOI 10.1007/s00103-008-0720-5

๑) Springer Medizin Verlag 2008

\section{Oxidativer Stress und Möglichkeiten seiner Messung aus umwelt- medizinischer Sicht}

\section{Mitteilung der Kommission „Methoden und Qualitätssicherung in der Umweltmedizin"}

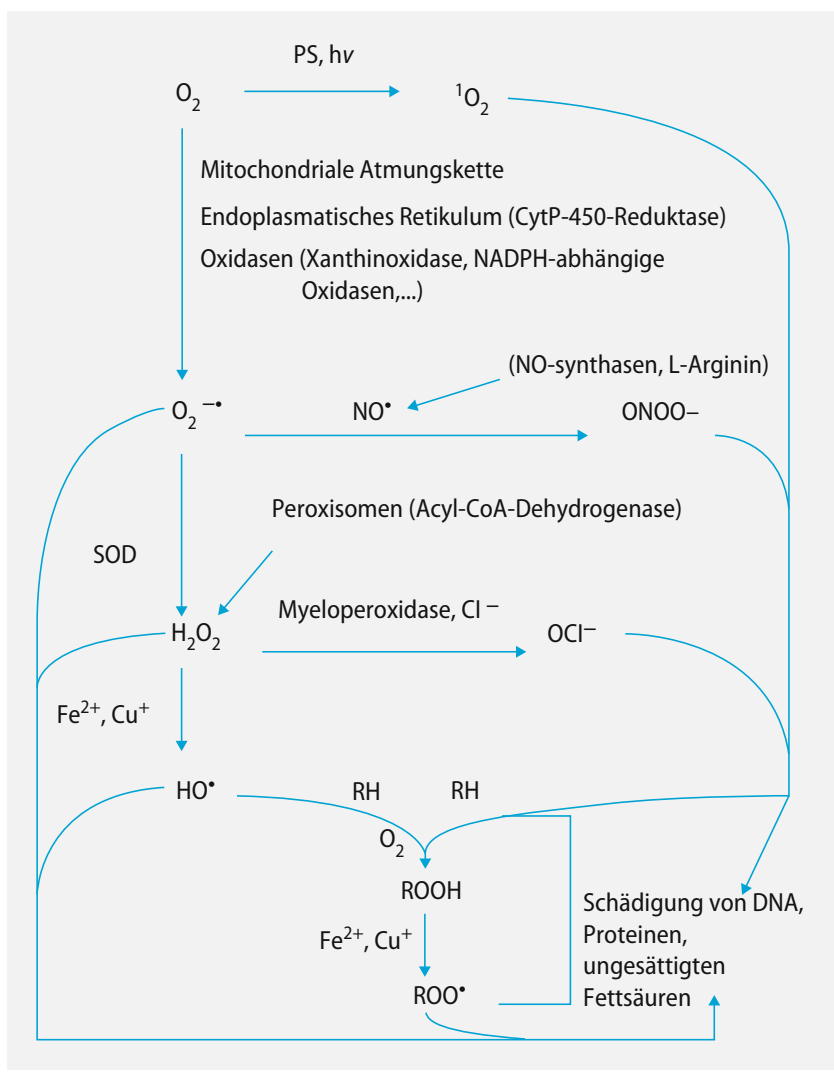

\section{Einleitung}

Reaktive Sauerstoffspezies (reactive oxygen species, ROS) kommen in aeroben Organismen überall und dauernd vor und haben wichtige physiologische Funktionen, sind aber auch als oxidativer Stress an unterschiedlichen Krankheitsgeschehen beteiligt. Zeitlebens ist der Mensch oxidativem Stress ausgesetzt. Das wissenschaftliche Interesse an ROS und den Gegenspielern, den Antioxidantien, ist groß. Zahlreiche Übersichtsarbeiten liegen vor $[8,9,10,11,12,13,14,15,16,17]$. Mehrere Mechanismen führen zur ROS-Bildung im Organismus ( $\bullet$ Abb. 1). Erstens wird ein Großteil des vom Körper aufgenommenen Sauerstoffs als Elektronenakzeptor für die Energiegewinnung in den Mitochondrien umgesetzt. Der weitaus größte Teil des Sauerstoffs wird hierbei zwar vollständig unter Bildung von Wasser reduziert, jedoch entstehen durch „fehlgeleitete“ Elektronen auch unvollständig reduzierte Sauerstoffspezies, wie etwa das Superoxidanionradikal $\left(\mathrm{O}_{2}{ }^{\bullet-}\right)$, sowie Folgeprodukte, $\mathrm{zu}$ denen Wasserstoffperoxid oder das Hydroxylradikal gehören. Zweitens existieren zahlreiche Oxidoreduktasen, also Enzyme wie Dehydrogenasen, Oxidasen und ähnliche, die im Rahmen normaler physiologischer Prozesse zur Bildung von reaktiven Sauerstoff- und Stickstoffspezies beitragen. Drittens werden bei Entzündungsprozes- sen von Makrophagen und anderen Zellen der Immunabwehr reaktive Sauerstoffund Stickstoffverbindungen zur Vernichtung von Mikroorganismen abgegeben. Viertens hat die Einwirkung einer Vielzahl exogener Noxen und Umwelteinflüsse beispielsweise von UV-Strahlung, Luftver- schmutzung (Ozon, Stickstoffoxide, verschiedene Stäube), aber auch einiger Medikamente und Industriechemikalien - die Bildung reaktiver Sauerstoffspezies zur Folge.

Aerobe Lebewesen verfügen über Mechanismen zum Schutz vor oxidativer 
Schädigung. So können ROS und reaktive Stickstoffspezies (RNS) inaktiviert, die Bildung dieser Spezies vermindert oder die verursachten Schäden repariert werden (• Tabelle 1a und $\mathbf{1 b}$ ).

Unter normalen physiologischen Bedingungen herrscht ein Fließgleichgewicht zwischen „oxidativen “ und ,antioxidativen“ Prozessen. Eine Auslenkung dieses Gleichgewichtes zugunsten der Bildung von oxidativ wirksamen Molekülen (Oxidantien) sowie der die Bildung von Oxidantien fördernden Vorstufen, der Prooxidantien, wird als „oxidativer Stress“ bezeichnet [18]. Ein solcher Zustand kann sowohl durch vermehrte Bildung von Prooxidantien als auch durch Verlust an Konzentration oder Aktivität von Antioxidantien hervorgerufen werden. Oxidativer Stress kann zu strukturellen Modifikationen körpereigener Moleküle führen, was den Verlust bestimmter Funktionen von Proteinen, Lipiden und DNA sowie Gewebeschädigungen nach sich ziehen kann. Oxidativer Stress ist die Ursache für akute Reperfusionsschädigungen [19] und akute Lungenschädigung nach Inhalation von reinem Sauerstoff [12]. Darüber hinaus ist oxidativer Stress mit der Entstehung zahlreicher chronischer Krankheiten, z. B. Krebs-, Herz-/Kreislauf-, neurodegenerativen und vielen anderen Erkrankungen assoziiert ( $\bullet$ Tabelle 2) [18, 20, 21, 22, 23, 24, 25]. Dabei ist bis heute unklar, inwieweit ein ursächlicher Zusammenhang besteht [26].

In der Toxikologie gehören der oxidative Stress und die Lipidperoxidation $\mathrm{zu}$ den grundsätzlichen Mechanismen chemisch-induzierter Zellschädigungen [27]. Untersuchungen bei Arbeitsplatz-exponierten Personen zeigen nicht selten Assoziationen zwischen Schadstoffexposition und oxidativem Stress [28, 29, 30, 31]. Deswegen ist die Frage von Interesse, ob auch Umwelteinflüsse das Risiko für oxidative Schädigungen erhöhen können [7, 32, 33, $34,35]$ und ob ein Schädigungsrisiko diagnostisch erfassbar ist [7, 32, 36]. Insgesamt besteht in der Medizin großes Interesse an Methoden zur Abschätzung oder gar Bestimmung des Ausmaßes an oxidativem Stress im Körper oder in einzelnen Kompartimenten. Diese Problematik ist jedoch sehr komplex, was durch eine Vielzahl reaktiver, oxidativ wirkender Moleküle be-

Bundesgesundheitsbl - Gesundheitsforsch - Gesundheitsschutz 2008 · 51:1464-1482 DOI 10.1007/s00103-008-0720-5

(C) Springer Medizin Verlag 2008

Empfehlung des Robert Koch-Instituts

\section{Oxidativer Stress und Möglichkeiten seiner Messung aus umwelt- medizinischer Sicht. Mitteilung der Kommission „Methoden und Qualitätssicherung in der Umweltmedizin"}

\section{Zusammenfassung}

Die Zahl der wissenschaftlichen Arbeiten, die sich mit dem Thema "oxidativer Stress" befassen, wächst stetig. Reaktive Sauerstoff- und Stickstoffspezies (ROS/RNS), die im Falle ihrer übermäßigen Bildung den Zustand des „oxidativen Stresses" hervorbringen können, werden sowohl im menschlichen Körper gebildet als auch von außen aufgenommen und können körpereigene Moleküle schädigen. Aufgrund von Daten, die eine Assoziation der Bildung von ROS/RNS mit zahlreichen Erkrankungen (Krebs-, Herz-/Kreislauf-, neurodegenerative Erkrankungen, sowie Diabetes mellitus, altersbedingte Makuladegeneration der Netzhaut) gezeigt haben, wird vermutet, dass ROS/RNS bei der Entstehung und Entwicklung dieser Krankheitsbilder eine wichtige Rolle spielen. Auch im Zusammenhang mit Umweltbelastungen wird in letzter Zeit die Beteiligung von oxidativem Stress diskutiert. Die Vermutung eines ursächlichen Zusammenhangs ist jedoch noch immer lediglich eine wissenschaftliche Arbeitshypothese, denn trotz jahrzehntelanger Forschung gibt es wenige verlässliche Aussagen zu den genauen molekularen Mechanismen, die der Bildung von ROS/RNS im Verlauf der genannten Erkrankungen sowie einer möglichen ursächlichen Beziehung zugrunde liegen. Es ist weiterhin unklar, welche der zahlreichen reaktiven Spezies, die sehr unterschiedliche chemische Eigenschaften besitzen, und welche der noch diverseren potenziellen Antioxidantien unter welchen Bedingungen von Relevanz für die Entstehung oder den Verlauf der jeweiligen Erkrankung sind. Trotz dieser Probleme und Unklarheiten wurden in den letzten Jahrzehnten zahlreiche Marker und Methoden zur Diagnostik des Zustandes "Oxidativer Stress" etabliert. Die vorliegende Arbeit gibt einen Überblick über verfügbare Messverfahren und hält aus methodischer Sicht folgende Verfahren für praktikabel: (i) Bestimmung von DNASchädigungsmarkern (8-Oxo-7,8-dihydro2'-desoxyguanosin) im Urin mithilfe von LC-MS, GC-MS, (ii) Bestimmung der Konzentration von Markern für die oxidative Lipidschädigung [8-Isoprostan (GC-MS)] und Malondialdehyd in Plasma/Urin (HPLC, GC-MS), (iii) die Bestimmung der Konzentration von Antioxidantien (Vitamine C, E). Jedoch kommt die Kommission des Robert Koch-Instituts "Methoden und Qualitätssicherung in der Umweltmedizin“ zu dem Schluss, dass beim derzeitigen Kenntnisstand weitere Studien erforderlich sind, bevor Messergebnisse im individualmedizinischen Bereich bei umweltmedizinischen Fragestellungen sinnvoll interpretiert werden können. 
dingt ist, die eine sehr unterschiedliche Spezifität und Reaktivität gegenüber potenziellen Zielmolekülen aufweisen. Dabei können sie unterschiedliche chemische Modifikationen an den Zielmolekülen verursachen. Gemäß obiger Definition des „oxidativen Stresses“ existieren prinzipiell 3 diagnostisch-analytische Herangehensweisen, nämlich zum einen die Bestimmung der Bildung reaktiver Spezies, zweitens die Bestimmung des Gehaltes an Antioxidantien im untersuchten Kompartiment sowie drittens die Analyse von
Schäden und Folgeprodukten der Einwirkung von ROS/RNS.

Die Messung reaktiver Moleküle in Körpergewebe oder Flüssigkeiten gestaltet sich wegen ihrer meist sehr niedrigen Konzentrationen und ihrer kurzen Lebensdauer schwierig. In $\bullet$ Tabelle 3 sind ausgewählte Radikale und ihre Halbwertszeiten aufgelistet. Es wird im Allgemeinen versucht, die Konzentrationen und Aktivitäten einzelner Antioxidantien und Folgeprodukte des oxidativen Stresses zu identifizieren und zu analysieren. Aller-

Tabelle 1a

Endogene enzymatische Antioxidantien im Plasma und Erythrozyten beim Menschen

\begin{tabular}{|lll}
\hline & Plasma (U/mI) & $\begin{array}{l}\text { Rote Blutkörperchen } \\
(\mathrm{U} / 1010 \text { Zellen) }\end{array}$ \\
\hline Katalase & 1139 & $3800-5400$ \\
\hline Superoxiddismutase & $5-20$ & $550-800$ \\
\hline Glutathionperoxidase & 0,4 & $7,8-10,6$ \\
\hline Glutathiondisulfid-Reduktase & 0,03 & $2,7-3,7$ \\
\hline Glutathion-S-Transferase & 0,005 & $1,5-2,5$ \\
\hline Thiole (R-SH) & $300-600(\mu \mathrm{M})$ & $2,2(\mu \mathrm{mol} / 1010$ Zellen) \\
\hline
\end{tabular}

Nach Referenz [90]

Tabelle 1b

Endogene nichtenzymatische Antioxidantien im Plasma beim Menschen

\begin{tabular}{|c|c|c|c|c|}
\hline $\begin{array}{l}\text { Konzentration } \\
\text { im Plasma ( } \mu \mathrm{M})\end{array}$ & $\begin{array}{l}\text { Optimale } \\
\text { Plasma- } \\
\text { konzentration } \\
(\mu \mathrm{M})\end{array}$ & $\begin{array}{l}\text { Empfohlene } \\
\text { tägliche Zufuhr }\end{array}$ & $\begin{array}{l}\text { Obere tägliche } \\
\text { Zufuhrmenge } \\
\text { ohne unerwünschte } \\
\text { Wirkungen }\end{array}$ & $\begin{array}{l}\text { Zufuhrmenge } \\
\text { mit bekannten } \\
\text { Nebenwirkungen }\end{array}$ \\
\hline
\end{tabular}

Lipidlösliche Antioxidantien

\begin{tabular}{|c|c|c|c|c|c|}
\hline $\begin{array}{l}\text { a-Tocopherol } \\
\text { oder Äquivalente }\end{array}$ & $12-46$ & $>30$ & $12-15 \mathrm{mg}$ & $200 \mathrm{mg}$ & $>800 \mathrm{mg}$ \\
\hline$\beta$-Carotin & $0,04-2,26$ & $>0,4$ & $2-6 \mathrm{mg}$ & $10 \mathrm{mg}$ & $>20 \mathrm{mga}$ \\
\hline a-Carotin & $0,02-0,47$ & & & & \\
\hline Lycopin & $0,05-1,40$ & $>0,4$ & & & \\
\hline Coenzym Q10 & $0,3-4,4$ & & $30 \mathrm{mg}$ & & \\
\hline \multicolumn{6}{|c|}{ Wasserlösliche Antioxidantien } \\
\hline Ascorbinsäure & $37-121$ & $>50$ & $100 \mathrm{mg}$ & $1000 \mathrm{mg}$ & \\
\hline \multicolumn{6}{|l|}{ Spurenelemente } \\
\hline Selen & $24-204 \mu \mathrm{g} / \mathrm{L}$ & $>50 \mu \mathrm{g} / \mathrm{L}$ & $30-70 \mu \mathrm{g}$ & $400 \mu \mathrm{g}$ & $>600 \mu \mathrm{g}$ \\
\hline Zink & & & $7-10 \mathrm{mg}$ & $30 \mathrm{mg}$ & $>110 \mathrm{mg}$ \\
\hline
\end{tabular}

$1 \mathrm{mg}$ Retinol-Äquivalent $=1 \mathrm{mg}$ Retinol = $6 \mathrm{mg}$ all-trans- $\beta$-Carotin; nach Referenz [90, 126], a höhere Dosen an $\beta$-Carotin als $20 \mathrm{mg} /$ Tag (Studiendauer 5-8 Jahre) oder 30 mg/Tag (Studiendauer 5,5 Jahre) zeigten, dass unter bestimmten Voraussetzungen (starkes Rauchen, erhöhter Alkoholkonsum oder Asbestexposition) das Lungenkrebsrisiko erhöht wird. 
Tabelle 2

\section{Erkrankungen, die mit oxidativem Stress assoziiert sind}

Herz-/Kreislauf-Erkrankungen Arteriosklerose, Kardiotoxizität des Adriamycins (Doxorubicin), Alkohol-Kardiomyopathie, Ischämie/ Reperfusionsschaden, ischämische Herzkrankheiten

\begin{tabular}{|c|c|}
\hline \multicolumn{2}{|l|}{ Krebserkrankungen } \\
\hline $\begin{array}{l}\text { Erkrankungen des } \\
\text { Nervensystems }\end{array}$ & $\begin{array}{l}\text { Schädel-Hirn-Trauma, inflammatorische Myopathie, } \\
\text { apoplektischer Insult, neurodegenerative Erkrankungen } \\
\text { (Alzheimer-Erkrankung, Parkinson-Krankheit, amyotrophe } \\
\text { Lateralsklerose) }\end{array}$ \\
\hline Erkrankungen der Augen & Altersbedingte Makula-Degeneration (AMD), Katarakt \\
\hline \multicolumn{2}{|l|}{ Diabetes mellitus } \\
\hline $\begin{array}{l}\text { Erkrankungen des } \\
\text { Verdauungstraktes }\end{array}$ & $\begin{array}{l}\text { Chronisch-entzündliche Darmerkrankungen, Pankreatitis, } \\
\text { alkoholische Leberzirrhose, Hepatitis, Fettleber }\end{array}$ \\
\hline Hauterkrankungen & Kutane Porphyrien, UV-induzierte Hautschädigung \\
\hline Lungenerkrankungen & $\begin{array}{l}\text { Lungenemphysem, Asthma, Asbestose, bronchopulmo- } \\
\text { nale Dysplasie }\end{array}$ \\
\hline Blutkrankheiten & $\begin{array}{l}\text { Fanconi-Anämie, Sichelzellenanämie, erythropoetische } \\
\text { Protoporphyrie }\end{array}$ \\
\hline \multicolumn{2}{|l|}{ Infektionen } \\
\hline $\begin{array}{l}\text { Allergische/Immunologische } \\
\text { Erkrankungen }\end{array}$ & Atopisches Ekzem, rheumatische Arthritis \\
\hline
\end{tabular}

Nach: [18, 19, 21, 22, 23]

Tabelle 3

\section{Ausgewählte freie Radikale und reaktive nichtradikalische Spezies}

\begin{tabular}{|c|c|}
\hline Reaktive Spezies & Halbwertzeit (sec, bei $37^{\circ} \mathrm{C}$ ) \\
\hline \multicolumn{2}{|l|}{ Radikale } \\
\hline HO^ (Hydroxylradikal) & $10^{-9}$ \\
\hline RO• (Alkoxylradikal) & $10^{-6}$ \\
\hline ROO` (Peroxylradikal) & 7 \\
\hline $\mathrm{O}_{2} \cdot-$ (Superoxidanionradikal) & Enzymatisch reguliert \\
\hline NO` (Stickstoffmonoxid) & $1-10$ \\
\hline \multicolumn{2}{|l|}{$\mathrm{NO}_{2}{ }_{2}$ (Stickstoffdioxid) } \\
\hline$Q^{\bullet-}$ (Semichinonradikale, etwa aus Zigarettenteer) & Tage \\
\hline \multicolumn{2}{|l|}{ Reaktive nichtradikalische Spezies } \\
\hline $\mathrm{H}_{2} \mathrm{O}_{2}$ (Wasserstoffperoxid) & Enzymatisch reguliert \\
\hline${ }^{1} \mathrm{O}_{2}$ (Singulettsauerstoff) & $10^{-6}\left(\right.$ in $\left.\mathrm{H}_{2} \mathrm{O}\right)$ \\
\hline \multicolumn{2}{|l|}{ HOCl (hypochlorige Säure) } \\
\hline 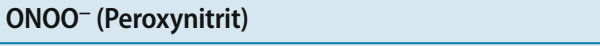 & $1(\mathrm{pH} 7,4)$ \\
\hline \multicolumn{2}{|l|}{$\mathrm{O}_{3}$ (Ozon) } \\
\hline Nach Referenzen $[127,128,129]$ & \\
\hline
\end{tabular}

ten der Ersteren charakterisiert ist und in dem im menschlichen Körper anfallende reaktive Spezies nicht ausreichend durch Antioxidantien neutralisiert werden können.
Prooxidantien: biologische, chemische oder physikalische Noxen, exogene und endogene Moleküle, die die Bildung reaktiver Sauerstoff- und Stickstoffspezies fördern.
Reaktive Sauerstoffspezies („reactive oxygen species", ROS): unter physiologischen Bedingungen reaktive, sauerstoffhaltige Moleküle.

Reaktive Stickstoffspezies („reactive nitrogen species", RNS): unter physiologischen Bedingungen reaktive, stickstoffhaltige Moleküle.

Freie Radikale: chemische Spezies (Atome, Moleküle, Ionen), die ein oder mehrere ungepaarte Elektronen besitzen und daher chemisch hochreaktiv sind.

Antioxidantien: Substanzen (Proteine, Peptide, niedermolekulare Verbindungen), die bei niedrigen Konzentrationen (im Vergleich zu oxidierbarem Substrat, z. B. körpereigenen Molekülen) die Oxidation dieses Substrats signifikant verlangsamen oder verhindern können [37].

Endogene antioxidative Faktoren: endogene antioxidative Schutzsysteme wie Enzyme, funktionelle Proteine, Peptide, niedermolekulare Metabolite.

Exogene antioxidative Faktoren: mit der Nahrung aufgenommene direkt oder indirekt antioxidativ wirkende Substanzen (Vitamine wie Vitamin C und E, Carotinoide, Polyphenole einschließlich der Flavonoide, sowie eine Reihe weiterer sekundärer Pflanzeninhaltsstoffe, die die Wirkung von prooxidativen Faktoren vermindern können).

Antioxidative Kapazität: Kumulative Fähigkeit und Effektivität der in einem untersuchten System vorliegenden Verbindungen, eine bestimmte reaktive Spezies zu neutralisieren.

Antioxidantienstatus: Konzentration/ Aktivität einzelner endogener und exogener antioxidativ wirkender Moleküle.

\section{Endogene und exogene Modulatoren des Gleichgewichtes zwischen Pro- und Antioxidantien}

Bei zahlreichen Erkrankungen wurden oxidative Veränderungen verschiedenster Art an biologisch bedeutsamen Makromolekülen nachgewiesen. Ob diese Modifikationen und die ihnen zugrunde liegende Bildung von ROS/RNS eine wichtige Rolle in der Pathogenese dieser Erkrankungen spielen oder ob sie lediglich eine Begleiterscheinung sind, ist im Einzelfall umstritten und bleibt zu klären. 


\section{Empfehlung des Robert Koch-Instituts}

Tabelle 4

Marker zur Erfassung des oxidativen Stresses

Marker Probenmaterial Methoden Kommentar

a) Marker der oxidativen DNA-Schädigung

8-0xo-7,8-dihydro-2'- Urin,

desoxyguanosin isolierte Zellen

HPLC-EC, GC-MS, Geeignete Methoden, besonders für Urinproben

8-Oxodihydroguanin (z. B. Lymphozyten)

Etheno-Addukte, Urin HPLC-MS-MS, Möglicherweise geeignete Methoden, besonders für

$\left(1, N^{6}\right.$-Ethenoadenin,

$1, \mathrm{~N}^{6}$-Etheno-2'-

32P-Postlabelling/HPLC Urinproben

desoxyadenosin,

Weitere Standardisierung notwendig

3, $\mathrm{N}^{4}$-Etheno-2'-

desoxycytidin)

Oxidierte Purin-,

Isolierte Zellen

Pyrimidinbasen

z. B. Lymphozyten)
Comet-Assay, DNA-Ent-

windung mit Einsatz von

DNA-Reparaturenzymen
Für wissenschaftliche Zwecke geeignet

Große Varianz von Werten zwischen verschiedene Methoden und Laboratorien, mögliche artifizielle Bildung von oxidativen DNA-Schäden während der Zellisolierung, Lagerung und Probenaufbereitung

\begin{tabular}{|c|c|c|c|}
\hline \multicolumn{4}{|c|}{ b) Marker der oxidativen Proteinschädigung } \\
\hline Carbonylgruppen & Plasma/Serum/Gewebe & $\begin{array}{l}\text { DNPH-Derivatisierung, } \\
\text { gefolgt von HPLC oder } \\
\text { immunchemischer } \\
\text { Detektion }\end{array}$ & $\begin{array}{l}\text { Sehr große Varianz von Werten zwischen verschiedenen } \\
\text { Methoden und Laboratorien [130] } \\
\text { Weitere Standardisierung der Probenaufbereitung not- } \\
\text { wendig }\end{array}$ \\
\hline $\begin{array}{l}\text { Oxidierte Thiol (SH)- } \\
\text { Gruppen, } \\
\text { Methioninsulfoxidreste } \\
\text { in Proteinen }\end{array}$ & $\begin{array}{l}\text { Gewebe, isolierte Zellen, } \\
\text { Plasma/Serum }\end{array}$ & $\begin{array}{l}\text { Derivatisierung + Spektro- } \\
\text { photometrie }\end{array}$ & $\begin{array}{l}\text { Für wissenschaftliche Zwecke geeignet } \\
\text { Mögliche artifizielle Oxidation während der Zellisolie- } \\
\text { rung, Lagerung und Probenaufbereitung } \\
\text { In vivo rasche Reparatur der oxidierten SH-Gruppen } \\
\text { möglich }\end{array}$ \\
\hline Tyrosindimere & $\begin{array}{l}\text { Plasma/Serum, Urin, } \\
\text { Gewebe, atherosklero- } \\
\text { tische Plaques }\end{array}$ & $\begin{array}{l}\text { HPLC mit Fluoreszenz- } \\
\text { detektion, } \\
\text { GC-MS }\end{array}$ & $\begin{array}{l}\text { Für wissenschaftliche Zwecke geeignet } \\
\text { Eventuell ein typisches Produkt der durch Myeoloperoxi- } \\
\text { dase (aktivierte Neutrophile) induzierten Oxidation von } \\
\text { Tyrosin } \\
\text { In der Praxis kaum erprobt }\end{array}$ \\
\hline $\begin{array}{l}\text { Hydroxyliertes Valin } \\
\text { und Leucin, } \\
\text { Oxidationsprodukte } \\
\text { des Lysins (Aminoadi- } \\
\text { pat-Semialdehyd) }\end{array}$ & Plasma & $\begin{array}{l}\text { Derivatisierung, HPLC mit } \\
\text { Fluoreszenzdetektion, } \\
\text { GC-MS, } \\
\text { immunologische } \\
\text { Methoden }\end{array}$ & $\begin{array}{l}\text { Für wissenschaftliche Zwecke geeignet } \\
\text { In der Praxis kaum erprobt }\end{array}$ \\
\hline
\end{tabular}

\section{c) Marker der oxidativen Lipidschädigung}

Lipidhydroperoxide Plasma/Serum, Serumfraktionen, Gewebe

\begin{tabular}{|lll}
\hline Isoprostane & $\begin{array}{l}\text { Urin, Plasma/Serum, } \\
\text { Serumfraktionen, } \\
\text { Gewebe, Atemkondensat }\end{array}$ & $\begin{array}{l}\text { GC-MS, } \\
\text { immunologische } \\
\text { Methoden } \\
\text { HPLC-MS-MS }\end{array}$ \\
\hline Malondialdehyd & $\begin{array}{l}\text { Urin, Plasma/Serum, } \\
\text { Serumfraktionen, Gewebe }\end{array}$ & $\begin{array}{l}\text { HPLC mit UV/Vis oder } \\
\text { Fluoreszenzdetektion } \\
\text { GC-MS }\end{array}$ \\
\hline
\end{tabular}

Oxidiertes LDL Serumfraktion ELISA

HPLC mit Chemilumineszenzdetektion mit Nachsäulenderivatisierung
Selten eingesetzt

Mögliche artifizielle Bildung von Lipidhydroperoxiden oder Abbau während Probenlagerung und -aufbereitung möglich

Geeignete Methode (Urin/Plasma)

Für immunologische Methoden weitere Standardisierung notwendig

Bei standardisierter Probenaufbereitung (Plasma/Urin), HPLC bzw. GC-MS eine relevante Methode

Potenziell geeignete Methode Weitere Standardisierung notwendig 
Tabelle 4

Marker zur Erfassung des oxidativen Stresses

\begin{tabular}{|c|c|c|c|}
\hline Marker & Probenmaterial & Methoden & Kommentar \\
\hline Ethan, Pentan & Atemluft & $\begin{array}{l}\text { GC, Cavity-Leak-Out- } \\
\text { Spektroskopie }\end{array}$ & $\begin{array}{l}\text { Selten eingesetzte Methode } \\
\text { Weitere Standardisierung notwendig }\end{array}$ \\
\hline \multicolumn{4}{|c|}{ d) Marker der antioxidativen Kapazität } \\
\hline $\begin{array}{l}\text { Endogene Antioxidan- } \\
\text { tien: } \\
\text { Superoxiddismutase } \\
\text { (SOD) } \\
\text { Katalase, Glutathion- } \\
\text { peroxidase, Gesamt- } \\
\text { thiole, } \\
\text { Glutathion (GSH) } \\
\text { Glutathiondisulfid- } \\
\text { Reduktase }\end{array}$ & $\begin{array}{l}\text { Plasma/Serum, Serum- } \\
\text { fraktionen, Gewebe }\end{array}$ & $\begin{array}{l}\text { Enzymatische Aktivitäts- } \\
\text { messungen } \\
\text { Immunochemische } \\
\text { Methoden, } \\
\text { Derivatisierung und } \\
\text { Photometrie oder HPLC } \\
\text { (Thiole) }\end{array}$ & $\begin{array}{l}\text { Messmethoden gut etabliert } \\
\text { Da verschiedene inflammatorische Mediatoren ein- } \\
\text { schließlich ROS/RNS die Expression bzw. Aktivität dieser } \\
\text { Enzyme erhöhen können, ist eine eindeutige Interpreta- } \\
\text { tion von Werten schwierig [131, 132, 133], z. B. falls er- } \\
\text { höhte Aktivität von diesen Enzymen gemessen wird, } \\
\text { kann man diesen Befund positiv interpretieren - guter } \\
\text { antioxidativer Schutz, oder negativ - erhöhte Produkti- } \\
\text { on von ROS/RNS oder Entzündungsprozess }\end{array}$ \\
\hline $\begin{array}{l}\text { Nutritive Antioxidan- } \\
\text { tien: } \\
\text { Tocopherole, Carotinoi- } \\
\text { de, Ascorbinsäure, } \\
\text { Spurenelemente (Se, } \\
\text { Zn) }\end{array}$ & $\begin{array}{l}\text { Urin, Plasma/Serum, } \\
\text { Serumfraktionen, Gewebe }\end{array}$ & HPLC & $\begin{array}{l}\text { Messmethoden gut etabliert } \\
\text { Erniedrigte Werte liefern einen Hinweis auf Mangelzu- } \\
\text { stände und erhöhtes Potenzial für oxidative Schädigung }\end{array}$ \\
\hline $\begin{array}{l}\text { Gesamte antioxidative } \\
\text { Kapazität: } \\
\text { TRAP } \\
\text { ORAC } \\
\text { TEAC } \\
\text { FRAP } \\
\text { PCL }\end{array}$ & $\begin{array}{l}\text { Urin, Plasma/Serum, } \\
\text { Serumfraktionen, Gewebe }\end{array}$ & $\begin{array}{l}\text { Fluorimetrie, Spektro- } \\
\text { photometrie, Chemilu- } \\
\text { mineszenz }\end{array}$ & $\begin{array}{l}\text { Messmethoden gut etabliert } \\
\text { Pathobiochemische Relevanz nicht geklärt } \\
\text { Siehe Text für weitere Bewertung }\end{array}$ \\
\hline
\end{tabular}

Blut-/Serumproben sollten als Nüchternblut entnommen werden. EC elektrochemische Detektion; GC Gaschromatographie; HPLC Hochleistungs-Flüssigchromatographie; MS Massenspektrometrie; AAS Atomabsorptionsspektrometrie; DNPH Dinitrophenylhydrazin

\section{Inflammatorische Prozesse}

Die erhöhte Produktion von ROS/RNS im Zuge inflammatorischer Prozesse, die wiederum an der Pathogenese zahlreicher Erkrankungen beteiligt sind, ist gut dokumentiert [38]. Einerseits werden im Verlauf des Entzündungsprozesses reaktive Spezies gebildet, etwa durch aktivierte Leukozyten im Zuge der Biosynthese von Prostaglandinen und Leukotrienen, oder vermittelt durch proinflammatorische $\mathrm{Zy}$ tokine wie TNF- $\alpha$, IL-1 und $\gamma$-Interferon. Diese stimulieren die Expression von Enzymen, die an der Entstehung reaktiver Spezies beteiligt sind, beispielsweise der induzierbaren Stickstoffmonoxid-Synthase (iNOS), die mit der Biosynthese von Stickstoffmonoxid $\left(\mathrm{NO}^{\bullet}\right.$ ) die Voraussetzung für die Bildung weiterer RNS, etwa des Peroxynitrits $\left(\mathrm{ONOO}^{-}\right)$, schaffen. Umgekehrt wird unter Einwirkung von
ROS/RNS die Synthese sowohl von Entzündungsmediatoren wie IL-1, IL-6 und TNF- $\alpha$ als auch von inflammatorischen Enzymen wie Cyclooxygenase-2 gefördert [39]. Bei ausgeprägter Entzündung kommt es oft zu lokaler Gewebeschädigung und Zelltod, Ereignisse, die wiederum die Produktion von ROS/RNS anregen können. Auf diese Weise ergibt sich eine enge Verzahnung zwischen Entzündungsprozess und erhöhter Produktion von ROS/RNS.

\section{Wirkung von Antioxidantien bei inflammatorischen Prozessen}

Trotz solcher experimenteller Befunde ist die antiinflammatorische Wirkung von bekannten Antioxidantien wie der Vitamine $\mathrm{C}$ und $\mathrm{E}$ - sofern überhaupt nachweisbar - sehr gering, was auf mehrere Faktoren zurückzuführen ist. Zum einen ist die Ansicht, exogen applizierte Anti- oxidantien könnten beim Menschen alle ROS/RNS komplett neutralisieren, irreführend. Tatsächlich kann wegen der hohen Reaktivität und recht kurzen Lebensdauer der ROS/RNS und der begrenzten maximal erreichbaren Antioxidans-Konzentrationen im Zielgewebe nur ein kleiner Teil der ROS/RNS durch ein bestimmtes exogenes Antioxidans neutralisiert werden. Zweitens ist nicht auszuschließen, dass ein Antioxidans aufgrund der einfachen Tatsache, dass es sich um ein redoxaktives Molekül handelt - im Zielgewebe tatsächlich als Prooxidans in Erscheinung tritt, was dem intendierten Nutzen entgegensteht. Drittens sind zahlreiche „nicht-antioxidative“ Wirkungen von Antioxidantien beschrieben worden, wie beispielsweise die Modulation zellulärer Signalwege, die im Widerspruch zu einer antiinflammatorischen Wirkung stehen könnten. 
Es ist somit festzustellen, dass der heutige Wissensstand zu den zwischen ROS/ RNS und Entzündungsprozess existierenden Regelkreisen sowie zur tatsächlichen Wirkungsweise von Antioxidantien im Zielgewebe noch zu lückenhaft ist, um Bedingungen beschreiben zu können, die einen gezielten Einsatz von Antioxidantien zur Entzündungskontrolle erlauben.

\section{Umwelteinflüsse}

Neben endogenen Faktoren wie Entzündungsmediatoren trägt eine Vielzahl exogener Noxen sowohl direkt als auch indirekt, beispielsweise über das Auslösen entzündlicher Prozesse, zur Entstehung oxidativer Schäden bei.

$\mathrm{Zu}$ den bekanntesten Faktoren gehören Umwelteinflüsse, wie die ultraviolette (UV) Strahlung der Sonne, Röntgen- und ionisierende Strahlung sowie Luftverschmutzung (Ozon, Feinstaub, Stickstoffoxide) $[5,40,41,42]$. Viele dieser Noxen wirken organspezifisch. So verursachen die ultravioletten Anteile der Sonnenstrahlung (UV-B, 280-320 nm; UV-A, $320-400 \mathrm{~nm}$ ) hauptsächlich eine Schädigung von Haut und Augen. UV-B und UV-A sind verantwortlich für eine Reihe pathologischer Phänomene der Haut wie entzündliche Reaktionen, Immunsuppression, Induktion von Hauttumoren, Photodermatosen und Lichtalterung der Haut. Unter Lichteinfluss und unter Beteiligung endogener (z. B. Porphyrin-Derivate) sowie exogen applizierter (z. B. Tetrazykline) Photosensibilisatoren gebildete ROS (wie $\mathrm{O}_{2}{ }^{\bullet-}$ ), Singulettsauerstoff $\left({ }^{1} \mathrm{O}_{2}\right)$, sind mitverantwortlich für Lipidperoxidation, Zellschädigung und Initiation sowie Verstärkung inflammatorischer Prozesse in der Haut $[43,44,45,46]$.

Auch Ozon kann Schadwirkung auf die Haut ausüben. So führen hohe Ozonkonzentrationen (10 ppm) zur Depletion von Antioxidantien wie des $\alpha$-Tocopherols (Vit. E) und der Ascorbinsäure (Vit. C) im Stratum corneum der Haut [47]. Deutlich niedrigere Ozonkonzentrationen (o,4 ppm, 2 Stunden) waren hingegen ausreichend, um entzündliche Reaktionen in der Lunge [48] und erhöhte Konzentrationen eines Markers der oxidativen Lipidschädigung (8-Isoprostan) in der Ausatemluft zu initiieren [49].
Die Wirkung von Partikeln auf die Atemwege hängt neben der chemischen Zusammensetzung der Partikel auch von der Größe der Partikel ab: Je kleiner ein Partikel ist, desto tiefer kann es in die Atemwege und von dort in das Lungengewebe eindringen. Makrophagen nehmen die Partikel in den Alveolen auf und transportieren sie in das Lungengewebe. Dort induzieren die Makrophagen einen Entzündungsprozess. Hinsichtlich der molekularen Mechanismen ist eine sehr enge Verbindung zwischen Entzündung, oxidativer Schädigung und Zytotoxizität festzustellen. Mögliche Mechanismen der Förderung der Bildung von ROS/RNS unter Einwirkung von Feinstaub und Ultrafeinstaub sind in einer Übersichtsarbeit zusammengefasst worden [50]. In der Tat steht urbane Luftverschmutzung, die auf Belastung mit Ozon, Feinstaub oder Stickstoffoxiden beruht, mit messbarer oxidativer Schädigung von Biomolekülen sowohl in Zellen des respiratorischen Traktes [gemessen als zur Bildung von 8-Oxo-7,8dihydro-2'-desoxyguanosin (8-oxo-dG) führende DNA-Schädigung] als auch systemisch (gemessen als Konzentration von Lipidperoxidationsprodukten im Blut) in Zusammenhang [51].

Auch Lebensstilfaktoren beeinflussen das Gleichgewicht zwischen Pro- und Antioxidantien. Zigarettenrauch enthält chemisch reaktive und oxidativ wirksame Stoffe, deren Beteiligung zum Beispiel auch an der Pathogenese der Arteriosklerose diskutiert wird [52, 53]. Rauchen erhöht die einzelnen Marker des oxidativen Stresses in unterschiedlichem Maße, wobei sowohl primäre Prozesse (oxidativ wirksame Stoffe) als auch sekundäre Prozesse (Entzündung der Atemwege) eine Rolle spielen können [54, 55, 56, 57, 58]. Auch körperliche Aktivität erhöht verschiedene Marker des oxidativen Stresses. Gleichzeitig induziert sie protektive Mechanismen, sodass anschließend die Suszeptibilität für oxidative Schädigung abnehmen kann [59, 60, 61, 62, 63, 64]. Dahingegen können durch Rotweinkonsum die Marker des oxidativen Stresses erniedrigt werden $[65,66,67]$.

$\mathrm{Zu}$ den exogenen Faktoren, die das Pro-/Antioxidans-Gleichgewicht im Organismus oder in einzelnen Geweben beeinflussen können, zählen neben Umwelt- einflüssen schließlich auch einzelne Medikamente sowie toxische Chemikalien [27], die oxidative Prozesse direkt oder indirekt, wie z. B. über eine Glutathion-Verarmung der Zellen, initiieren können. Bekannte Stoffe sind Paracetamol (Acetaminophen), verschiedene Alkohole, Tetrachlorkohlenstoff, das Herbizid Paraquat oder einige Schwermetalle [68, 69, $70,71,72]$.

Zusammenfassend kann gesagt werden, dass eine erhöhte Produktion von ROS/RNS im menschlichen Körper oft sekundär als Folge entzündlicher Prozesse oder der Einwirkung exogener Noxen auftritt. Weiterhin spielt auch der Lebensstil eine wichtige Rolle. Von einigen Autoren wird die Bildung von ROS/RNS sowie von Produkten der Interaktion dieser Spezies mit körpereigenen Molekülen als „Surrogat-Marker" für diese Prozesse herangezogen.

\section{Nachweis eines Ungleich- gewichtes zwischen Pro- und Antioxidantien-Marker für oxidativen Stress}

\section{DNA-Schädigung}

Durch DNA-Schädigung entstehende Verbindungen wie 8-Oxo-7,8-dihydro-2'desoxyguanosin (8-oxo-dG) und 8-Oxodihydroguanin (8-oxo-Gua) oder EthenoAddukte von DNA-Basen (z. B. 1, N6 Ethenoadenin) und Nukleosiden (z. B. 1, $\mathrm{N}^{6}$-Etheno-2'-desoxyadenosin, 3, $\mathrm{N}^{4}$ Etheno-2'-desoxycytidin) haben sich als Indikatoren für oxidativen Stress erwiesen und wurden in verschiedenen Zellen und im Urin identifiziert [73, 74]. 8-oxo-dG und 8-oxo-Gua sind die meistuntersuchten Oxidationsprodukte der DNAOxidation. Eine Reihe von chromatographischen Methoden wie HPLC-EC, GCMS, HPLC-MS, HPLC-MS/MS wird zur Messung von 8-oxo-(d)G im Urin oder in isolierten Zellen (wie z. B. peripheren Lymphozyten) eingesetzt [4]. Darüber hinaus wurden immunchemische Methoden beschrieben, die diesen DNA-Oxidationsmarker erfassen [75, 76, 77]. Weitere sehr häufig eingesetzte und in der wissenschaftlichen Literatur beschriebene Methoden zur Detektion oxidativer DNASchädigung in Zellen umfassen die Ein- 
zelzellgelelektrophorese („comet assay“) und auf Einsatz isolierter bakterieller Reparaturenzyme beruhende Ansätze wie Formamidopyrimidin-DNA-Glycosylase (Fpg) oder Endonuclease III in Kombination mit der Methode der alkalischen DNA-Entwindung („alkaline unwinding“).

Der Vorteil für die Messungen von DNA-Oxidationsmarkern im Urin gegenüber isolierten Zellen, wie z. B. in peripheren Lymphozyten, besteht vor allem darin, dass die DNA-Oxidationsprodukte im Urin aus dem ganzen Organismus stammen. Die Untersuchungen von isolierten Lymphozyten widerspiegeln jedoch die oxidativen Prozesse nur in diesen Zellen und nicht unbedingt im ganzen Organismus.

Einige der genannten Methoden wurden im Rahmen eines durch die EU geförderten Projektes (European Standards Committee on Oxidative DNA Damage; ESCODD) verglichen und validiert. Die am ESCODD-Konsortium beteiligten Arbeitsgruppen mit langjährigen Erfahrungen mit Analysen der DNA-Schädigung haben hierzu dieselben Proben mit den jeweils gleichen Methoden untersucht. Die Messungen ergaben sehr große Unterschiede zwischen den Labors für die in diesen Proben ermittelten Werte. Das deutet auf dringenden Verbesserungsbedarf hin, insbesondere für die Routineanwendung in der Praxis [74, 78].

\section{Lipidoxidation}

Die am häufigsten eingesetzten Marker zur Bestimmung des oxidativen Stresses sind Produkte der oxidativen Modifikation von ungesättigten Fettsäuren (vgl. - Tabelle 4).

\section{Lipidhydroperoxide}

Eine Vielzahl reaktiver Moleküle reagiert direkt oder indirekt mit ungesättigten Fettsäuren (• Abb. 1). Dies führt über intermediär gebildete Fettsäureradikale zur Bildung von Fettsäureperoxylradikalen, die unter Reaktion mit einem weiteren Fettsäuremolekül oder einem Antioxidans zu Fettsäurehydroperoxiden umgesetzt werden. In biologischen Systemen reagieren die Fettsäurehydroperoxide mit Sulfhydrylgruppen von Proteinen, mit Über- gangsmetallionen, wie Eisen (Fe) oder Kupfer $(\mathrm{Cu})$, oder werden durch die Phospholipidhydroperoxid-Glutathionperoxidase reduziert. Es gibt einige Methoden zur Bestimmung von Lipidhydroperoxiden, beispielsweise die iodometrische Messung oder die Bestimmung mittels HPLC mit Chemilumineszenzdetektion nach erfolgter Nachsäulenderivatisierung. Die iodometrische Methode ist bei einfachen chemischen oder biologischen Systemen, in denen die Lipide bzw. die Lipidhydroperoxide konzentriert vorliegen und eine hohe Stabilität aufweisen, gut geeignet. Im humanen Plasma allerdings sind Konzentration und Stabilität von Lipidhydroperoxiden zu niedrig und die Matrix zu komplex, als dass durch deren Bestimmung korrekte Ergebnisse erhalten werden könnten. Die Lipidhydroperoxidbestimmung im Plasma mittels HPLC mit Chemilumineszenzdetektion ist eine technisch aufwendige und selten eingesetzte Methode.

\section{Isoprostane}

Isoprostane sind Prostaglandinisomere, die ohne Beteiligung der Cyclooxygenase aus Arachidonsäure gebildet werden können. Das am besten untersuchte und am häufigsten quantifizierte Isoprostan ist das 8-Isoprostaglandin- $\mathrm{F}_{2 \alpha}$ (8-Isoprostan). Neben der Bildung durch Radikalkettenreaktion nach oxidativer Schädigung von Arachidonsäure entsteht 8-Isoprostaglandin- $\mathrm{F}_{2 \alpha}$ auch zu etwa $10 \%$ in der durch Cyclooxygenase katalysierten enzymatischen Umsetzung der Arachidonsäure $[79,80]$. In der Literatur werden Konzentrationen von Isoprostanen im Plasma gesunder Menschen mit 42 bis $443 \mathrm{pg} / \mathrm{ml}$ angegeben [81, 82]. Bestimmte Verhaltensweisen und Lebensbedingungen sowie Krankheiten lassen die Konzentration in Urin und Plasma ansteigen. So erhöht vermehrter Alkoholkonsum dosisabhängig die Ausscheidung von Isoprostanen mit dem Urin [83]. Bei Patienten mit alkoholbedingter Leberzirrhose oder alkoholinduzierter Hepatitis konnte ebenfalls eine erhöhte 8-iso-PGF ${ }_{2 \alpha}$-Konzentration im Urin festgestellt werden [84]. Auch Raucher zeigten erhöhte Isoprostanwerte in Urin und Plasma $[85,86]$. Eine vermehrte Bildung von Isoprostanen wurde für zahlreiche Erkrankungen beschrieben, darun- ter Arteriosklerose, Diabetes mellitus (Typ 1 und 2), Hypercholesterinämie, Präeklampsie und Alzheimer (eine Übersicht hierzu findet sich in Ref. [87]).

Isoprostan-Konzentrationen können mittels an Massenspektrometrie gekoppelte Gaschromatographie (GC-MS) und HPLC genau und reproduzierbar bestimmt werden. Allerdings ist die Methode in Aufarbeitung und Analyse sehr aufwendig. ELISA-Techniken stehen für den Nachweis von Isoprostanen ebenfalls zur Verfügung, sind aber - obgleich sehr viel einfacher handhabbar - in der Praxis leider noch nicht ausreichend evaluiert.

\section{Malondialdehyd}

Peroxylradikale, die aus Fettsäuren mit drei und mehr Doppelbindungen hervorgehen, reagieren über ein intermediäres cyclisches Endoperoxid unter anderem zu Malondialdehyd (MDA). MDA ist ein reaktionsfreudiges Molekül und findet sich im Plasma hauptsächlich an Aminosäureresten in Proteinen gebunden, vornehmlich an Lysin- und Cysteinresten. MDA ist einer der am häufigsten bestimmten Marker der In-vivo-Lipidoxidation. Unter physiologischen Bedingungen wurden Konzentrationen von gesamtem, also gebundenem und freiem MDA im Blutplasma je nach Messverfahren zwischen 0,1 und $15 \mu \mathrm{M}$ angegeben.

Diese große Spanne scheint darauf hinzuweisen, dass MDA-Messungen im Plasma schlecht reproduzierbar sind. Jedoch zeigen die in $\bullet$ Tabelle 5 aufgeführten Ergebnisse, dass unter ähnlichen Hydrolyse-, Derivatierungs- und Detektionsbedingungen der Normalbereich der MDA-Konzentration im Plasma in Studien aus unterschiedlichen Ländern ähnlich ist. So liegt beispielsweise bei saurer Hydrolyse (ortho-Phosphorsäure, Essigsäure, Trifluoressigsäure, Perchlorsäure), Derivatisierung mit Thiobarbitursäure (TBA) und Fluoreszenz- oder UV/Vis-Detektion nach Trennung mittels HPLC der obere Referenzwert (97,5. Perzentil) bei o,83 bis 1,24 $\mu \mathrm{M}$. Nach alkalischer Hydrolyse mit anschließender Derivatisierung mit TBA zeigt sich hingegen eine Spreizung des oberen Referenzwertes (o,55-1,79 $\mu \mathrm{M})$.

Noch zu Beginn der 1990er-Jahre wurden deutlich niedrigere MDA-Plasmakonzentrationen bestimmt, wenn die Pro- 


\section{Empfehlung des Robert Koch-Instituts}

Tabelle 5

Methoden zur Bestimmung von Malondialdehyd sowie Malondialdehyd-Plasmakonzentrationen

Literatur (Land) Methode Derivatisierung: Reagenzien, Inkubation (Temperatur, Zeit) Referenzbereich $m \pm S D(\mu M)$ $(\mu \mathrm{M}) \mathrm{m} \pm 1,96 \times \mathrm{SD}$

Aufarbeitung: Saure Hydrolyse, $\mathrm{H}_{3} \mathrm{PO}_{4}, \mathrm{TBA}$

Ref. [134] Dänemark HPLC EDTA-Plasma, $\mathrm{H}_{3} \mathrm{PO}_{4}, \mathrm{TBA}, 100^{\circ} \mathrm{C} / 1 \mathrm{~h} \quad 0,36-1,24$

\begin{tabular}{|c|c|c|c|c|}
\hline & & & $n=213$ & \\
\hline \multirow[t]{2}{*}{ Ref. [135] USA } & HPLC & EDTA-Plasma, BHT, $\mathrm{H}_{3} \mathrm{PO}_{4}, \mathrm{TBA}, 100^{\circ} \mathrm{C} / 1 \mathrm{~h}$ & $0,43-0,95$ & $0,69 \pm 0,13$ \\
\hline & & & $n=10$ & \\
\hline \multirow[t]{2}{*}{ Ref. [136] USA } & HPLC & EDTA-Plasma, $\mathrm{H}_{3} \mathrm{PO}_{4}, \mathrm{TBA}, 100^{\circ} \mathrm{C} / 1 \mathrm{~h}$ & $0,34-0,86$ & $0,6 \pm 0,13$ \\
\hline & & & $n=41$ & \\
\hline \multirow[t]{2}{*}{ Ref. [137] Schweden } & HPLC & EDTA-Plasma, $\mathrm{H}_{3} \mathrm{PO}_{4}, \mathrm{TBA}, 100^{\circ} \mathrm{C} / 1 \mathrm{~h}$ & $0,50-1,22$ & $0,86 \pm 0,18$ \\
\hline & & & $n=103$ & \\
\hline \multirow[t]{2}{*}{ Ref. [138] Taiwan } & HPLC & EDTA-Plasma, $\mathrm{BHT}, \mathrm{H}_{3} \mathrm{PO}_{4}, \mathrm{TBA}, 100^{\circ} \mathrm{C} / 30 \mathrm{~min}$ & $0,31-1,16$ & $0,75 \pm 0,22$ \\
\hline & & & $n=16$ & \\
\hline
\end{tabular}

Aufarbeitung: Saure Hydrolyse, Acetat oder TCA oder TFA, TBA

\begin{tabular}{|c|c|c|c|c|}
\hline Ref. [139] Japan & HPLC & EDTA-Plasma, TBA, Na-Acetat, $\mathrm{pH} 3,5,95^{\circ} \mathrm{C} / 1 \mathrm{~h}$ & $\begin{array}{l}0,36-1,00 \\
n=13\end{array}$ & $0,68 \pm 0,16$ \\
\hline Ref. [140] Kanada & HPLC & EDTA-Plasma, TBA, Na-Acetat pH 3,5 mit DETPA, BHT, $95^{\circ} \mathrm{C} / 45 \mathrm{~min}$ & $\begin{array}{l}0,71-0,96 \\
n=25\end{array}$ & \\
\hline Ref. [141] BRD & HPLC & EDTA-Plasma, TBA, TFA, BHT, $95^{\circ} \mathrm{C} / 45 \mathrm{~min}$ & $\begin{array}{l}0,12-0,83 \\
n=22\end{array}$ & $0,46 \pm 0,17$ \\
\hline Ref. [142] Spanien & HPLC & Serum, TBA, Perchlorsäure, $95^{\circ} \mathrm{C} / 45 \mathrm{~min}$ & $\begin{array}{l}0,21-0,89 \\
n=68\end{array}$ & $0,55 \pm 0,17$ \\
\hline Ref. [143] Italien & HPLC & Citrat-Plasma, TBA, Na-Acetat, mit DTPA, pH 3,5, BHT, $95^{\circ} \mathrm{C} / 45 \mathrm{~min}$ & $\begin{array}{l}0-2,134 \\
n=15 \text { Männer } \\
0,046-2,446 \\
n=10 \text { Frauen }\end{array}$ & $\begin{array}{l}0,906 \pm 0,614 \\
1,246 \pm 0,600\end{array}$ \\
\hline
\end{tabular}

Aufarbeitung: Alkalische Hydrolyse, $\mathrm{NaOH}, \mathrm{TBA}$

Ref. [144] Frankreich HPLC Heparin-Plasma, EDTA, NaOH, Perchlorsäure, TBA

$0,33-0,55 \quad 0,43 \pm 0,05$

$\mathrm{n}=30$

Ref.[145] Tschechien HPLC EDTA-Plasma, NaOH, EDTA, BHT, $60^{\circ} \mathrm{C} / 30 \mathrm{~min}$

$0,37-0,89$

$0,13 \pm 0,63$

Acetat, pH 3, TBA, $100^{\circ} \mathrm{C} / 1 \mathrm{~h}$

$\mathrm{n}=40$

Citrat-Plasma, $\mathrm{NaOH}, \mathrm{EDTA}, \mathrm{BHT}, 60^{\circ} \mathrm{C} / 30 \mathrm{~min}$

$0,61-2,57$

Acetat $\mathrm{pH} 3, \mathrm{TBA}, 100^{\circ} \mathrm{C} / 1 \mathrm{~h}$

$\begin{array}{llll}\text { Ref. [138] Taiwan } \quad H P L C & \text { Heparin-Plasma, } \mathrm{BHT}, \mathrm{NaOH} & 1,11-1,79 & 1,45 \pm 0,17 \\ & 60^{\circ} \mathrm{C} / 30 \mathrm{~min} \\ & \mathrm{TCA}, \mathrm{KI}, \mathrm{TBA}, 95^{\circ} \mathrm{C} / 30 \mathrm{~min} & \end{array}$

Aufarbeitung: Alkalische Hydrolyse; Dinitrophenylhydrazin (DNPH); Diaminonaphthalin (DAN), 9-Fluorenylmethoxycarbonylhydrazin (9-FMOC)

\begin{tabular}{|c|c|c|c|c|}
\hline Ref. [146] Australien & HPLC & EDTA-Plasma, BHT, NaOH, DNPH & $\begin{array}{l}>16,44 \\
n=20\end{array}$ & $13,8 \pm 1,32$ \\
\hline Ref. [147] BRD & HPLC & EDTA-Plasma, $\mathrm{NaOH}, 60^{\circ} \mathrm{C} / 30 \mathrm{~min}$, Perchlorsäure, DNPH, $60^{\circ} \mathrm{C} / 30 \mathrm{~min}$ & $\begin{array}{l}1,58-2,74 \\
n=12\end{array}$ & $2,16 \pm 0,29$ \\
\hline Ref. [148] Frankreich & HPLC & Heparin-Plasma, $\mathrm{DAN}, \mathrm{HCl}, 37^{\circ} \mathrm{C} / 180 \mathrm{~min}$ & $\begin{array}{l}0,082-0,194 \\
n=19\end{array}$ & $0,138 \pm 0,028$ \\
\hline Ref. [149] China & HPLC & $\begin{array}{l}\text { Heparin-Plasma, } \mathrm{H}_{2} \mathrm{SO}_{4} \text { Raumtemperatur } / 60 \mathrm{~min} \\
\text { 9-FMOC, } 50^{\circ} \mathrm{C} / 4 \mathrm{~h}\end{array}$ & $\begin{array}{l}0,37-0,48 \\
n=15\end{array}$ & $0,43 \pm 0,30$ \\
\hline
\end{tabular}

Aufarbeitung: Gaschromatographie-Massenspektrometrie (GC-MS)

$\begin{array}{llll}\text { Ref. [88] USA GC-MS Heparin-Plasma, } \mathrm{H}_{2} \mathrm{SO}_{4} \text {, Pentafluorophenylhydrazin } & 0,025-0,038\end{array}$

$\mathrm{n}=6$ 
Tabelle 5

Methoden zur Bestimmung von Malondialdehyd sowie Malondialdehyd-Plasmakonzentrationen

\begin{tabular}{|c|c|c|c|c|}
\hline Literatur (Land) & Methode & Derivatisierung: Reagenzien, Inkubation (Temperatur, Zeit) & $\begin{array}{l}\text { Referenzbereich } \\
(\mu \mathrm{M}) \mathrm{m} \pm 1,96 \times \mathrm{SD}\end{array}$ & $\mathrm{m} \pm \mathrm{SD}(\mu \mathrm{M})$ \\
\hline Ref. [89] Italien & GC-MS & EDTA-Plasma, NaOH, Phenylhydrazin & $\begin{array}{l}1,16-1,44 \\
n=70\end{array}$ & $1,3 \pm 0,07$ \\
\hline Ref. [150] Italien & GC-MS & keine Hydrolyse, Pentafluorobenzylhydrazin & 0,20 & \\
\hline
\end{tabular}

TBA Thiobarbitursäure; TCA Trichloressigsäure; TFA Trifluoressigsäure; $\mathrm{H}_{3} \mathrm{PO}_{4}$ ortho-Phosphorsäure; $\mathrm{BHT}$ 2,6-Di-tert.-Butylhydroxytoluol; $\mathrm{H}_{2} \mathrm{SO}_{4}$ Schwefelsäu$r e ; \mathrm{m} \pm$ SD Mittelwert \pm Standardabweichung

ben mittels GC-MS anstelle der HPLC mit optischen Detektionsmethoden analysiert wurden. Der Unterschied wurde auf die mögliche artifizielle MDA-Bildung während der Probenvorbereitungen für die HPLC-Messung zurückgeführt, weshalb für einige Zeit die GC-MS-Analyse als Methode der Wahl zur Bestimmung von MDA im Plasma betrachtet wurde. Es konnte jedoch gezeigt werden, dass unter anderen Hydrolysebedingungen $(\mathrm{NaOH}$ statt $\mathrm{H}_{2} \mathrm{SO}_{4}$, $\bullet$ Tabelle 5; vgl. Ref. [88, 89]) die per GC-MS bestimmten MDA-Konzentrationen im Plasma den per HPLCAnalyse bestimmten gleichen.

Thiobarbitursäure (TBA) gehört zu den am häufigsten eingesetzten Derivatisierungsmitteln. Dabei reagiert MDA bei hoher Temperatur $\left(95-100^{\circ} \mathrm{C}\right)$ und niedrigem $\mathrm{pH}$-Wert ( $\mathrm{pH}$ 2-4) mit zwei Molekülen TBA zu einem Farbkomplex mit hohem Extinktionskoeffizienten, dessen Absorption bei $532 \mathrm{~nm}$ gemessen werden kann. Zusätzlich ist eine fluorimetrische Bestimmung des Farbkomplexes möglich. Nachteile dieser Derivatisierungsbedingungen sind mögliche Reaktionen von TBA mit verschiedenen Biomolekülen unter der Bildung von weiteren Farbkomplexen sowie die artifizielle Bildung von MDA aus ungesättigten Fettsäuren, Lipidperoxiden oder anderen organischen Molekülen, wie Kohlenhydraten oder Aminosäuren. Die HPLC-Methode mit Fluoreszenz- oder UV/Vis-Detektion, die die chromatographische Trennung des MDA$\mathrm{TBA}_{2}$-Komplexes von anderen Farbkomplexen erlaubt, ist somit notwendig, um bei niedrigen MDA-Konzentrationen in komplexen biologischen Proben, beispielsweise Plasma, korrekte Ergebnisse zu erzielen. Nicht-chromatographische spektrophotometrische oder spektrofluo- rimetrische Methoden zur MDA-Messung sind deshalb nicht zu empfehlen.

Derzeit gibt es keine Methode, mit der die absolute Konzentration an (freiem und gebundenem) MDA im Plasma bestimmt werden kann. Unter definierten Bedingungen von Hydrolyse, Derivatisierung und Erfassung des Farbkomplexes werden jedoch reproduzierbare Ergebnisse erzielt. Die gemessenen Konzentrationen entsprechen wahrscheinlich nicht dem gesamten im Plasma enthaltenen MDA, sind aber ein Maß für einen bestimmten Anteil von MDA im Plasma unter den gewählten Bedingungen. Trotz dieser bekannten Einschränkungen kann die Bestimmung von MDA in Plasma/ Urin mithilfe der GC-MS- oder durch TBA-Derivatisierung/HPLC Information bezüglich des Status des oxidativen Stresses im menschlichen Körper liefern.

\section{Antioxidantienstatus}

Die Konzentration einzelner ROS/RNS wird durch ein Netzwerk antioxidativer Verteidigungssysteme, die sehr vielfältig und auf mehreren Ebenen (Prävention, direkte Inaktivierung und Reparatur) organisiert sind, kontrolliert. Im Falle zu niedriger Antioxidantienkonzentrationen steigt das Risiko für oxidative Schädigung. Die Feststellung eines Verlustes an Antioxidantien gibt aber keine Information darüber, ob eine solche Schädigung bereits eingetreten ist oder nicht. $\mathrm{Zu}$ den vom Körper selbst gebildeten endogenen Antioxidantien gehören auf die Inaktivierung spezifischer ROS/RNS spezialisierte antioxidative Enzyme, z. B. Glutathionperoxidasen oder Superoxiddismutasen. Die Regulation von Konzentration und Aktivität dieser Enzyme ist komplex. So werden sie etwa durch das Angebot und die Zufuhr essenzieller Enzymbestandteile, wie die Spurenelemente Selen (für Glutathionperoxidasen) oder $\mathrm{Cu}, \mathrm{Zn}, \mathrm{Mn}$ (für Superoxiddismutasen), beeinflusst. Auch können Substrate der endogenen antioxidativen Enzyme (in diesem Fall ROS/RNS) die Neusynthese der Enzyme induzieren. Harnsäure oder Bilirubin zählen zu den endogenen niedermolekularen Antioxidantien und können einige ROS abfangen. Andererseits sind sie zugleich Metabolite biochemischer Reaktionen, die zur Ausbildung eines oxidativen Stresses beitragen. So ist Harnsäure zwar einerseits ein sehr gutes Antioxidans, geht jedoch andererseits aus der Oxidation des Xanthins hervor. Diese Reaktion wird zu gewissen Teilen von der Xanthinoxidase katalysiert und verläuft unter Sauerstoffverbrauch bei gleichzeitiger Bildung von Superoxid und Wasserstoffperoxid.

Weiterhin gehören Thiolgruppen der Aminosäure Cystein oder von Cysteinresten in Proteinen oder Peptiden (etwa des Glutathions) zu den wichtigsten endogenen Antioxidantien. Thiolgruppen können direkt mit ROS/RNS reagieren oder sind indirekt an der Inaktivierung von Peroxiden oder Peroxynitrit durch antioxidative Enzyme wie Glutathionperoxidasen beteiligt. Durch diese Reaktionen werden Thiolgruppen oxidiert. Reduktasen wie Glutathiondisulfidreduktase oder Thioredoxinreduktase sind verantwortlich für eine schnelle Reduktion (Regenerierung) der oxidierten Thiolgruppen. Cystein ist eine bedingt essenzielle Aminosäure, die im Organismus aus der essenziellen Aminosäure Methionin synthetisiert werden kann. Ein Cysteinmangel kann demnach durch Minderversorgung mit Cystein oder Methionin (bei 


\section{Empfehlung des Robert Koch-Instituts}

Erwachsenen $<12 \mathrm{mg} / \mathrm{Tag}$ ) zustande kommen. Eine wichtige Rolle für die Prävention oxidativer Schädigung spielen weiterhin Proteine wie Coeruloplasmin, Transferrin oder Laktoferrin, die an der Produktion von ROS beteiligte Übergangsmetallionen wie $\mathrm{Cu}$ und $\mathrm{Fe}$ binden [90].

Exogene Antioxidantien sind Verbindungen, die dem Organismus mit der Nahrung zugeführt werden. $\mathrm{Zu}$ den bekanntesten gehören einige Vitamine, die antioxidative Eigenschaften besitzen, wie die Vitamine $\mathrm{C}$ und $\mathrm{E}$ sowie sekundäre Pflanzenstoffe wie Carotenoide ( $\beta$-Carotin, Lycopin, Lutein) und Polyphenole (einschließlich der Flavonole, Isoflavonoide und Catechine). Die Konzentrationen dieser Verbindungen in Blutplasma und anderen Kompartimenten ist von Zufuhr, Absorption und Abbau sowie Oxidation durch ROS/RNS abhängig. Referenzbereiche und gegenwärtig als optimal eingestufte Plasmakonzentrationen exogener Antioxidantien sind in den $\bullet$ Tabelle 1a und $\mathbf{1 b}$ aufgeführt.

Eine niedrigere als die optimale/untere Referenzbereichkonzentration exogener und endogener Antioxidantien ist mit einer erhöhten Wahrscheinlichkeit an oxidativer Schädigung verbunden und ist ein Marker für oxidativen Stress.

Die Methoden zur Bestimmung der Plasma-Konzentrationen antioxidativer Vitamine (C, E), Carotenoide und Thiole sind in der Literatur ausgiebig beschrieben $[91,92]$.

\section{Gesamte antioxidative Kapazität}

Die Tatsache, dass im Organismus eine Vielzahl antioxidativ wirksamer Komponenten existiert, die gemeinsam ein effektives antioxidatives Netzwerk etablieren, sowie die Einsicht, dass die Bestimmung der Konzentration nur einiger weniger dieser Komponenten in nur einigen wenigen Kompartimenten, die der Messung zugänglich sind, nicht das Gesamtbild widerspiegelt, hat zu der nachvollziehbaren Tendenz geführt, in einfachen Analysen eine gesamte antioxidative Kapazität („,total antioxidant capacity“, TAC) bestimmen zu wollen anstatt einzelne ausgewählte Antioxidantien. Die gesamte antioxidative Kapazität entspricht dabei der

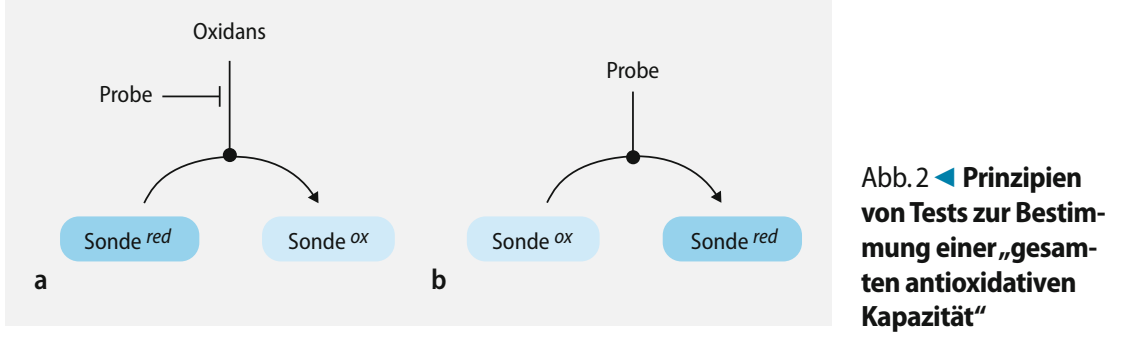

Fähigkeit einer Probe (Plasma, Lebensmittel- oder Gewebehomogenat, aber auch chemische Verbindung), in einem Testsystem ein bestimmtes reaktives Molekül (Radikal) abzufangen oder zu neutralisieren. Hinter dem Einsatz solcher Tests in der biomedizinischen Forschung steht weiterhin die Hypothese, dass eine erhöhte antioxidative Kapazität im Serum auf die Fähigkeit hinweist, eine mit einer höheren Belastung an ROS/RNS einhergehende Situation besser bewältigen zu können, sowie dass eine höhere antioxidative Kapazität einer Probe indirekt auf eine höhere Konzentration oder günstigere Zusammensetzung von Antioxidantien in der Probe hindeutet.

\section{Beschreibung ausgesuchter Testvarianten}

In der Literatur ist eine große Zahl verschiedener Tests zur Bestimmung der gesamten antioxidativen Kapazität einer Probe beschrieben. Am häufigsten werden Tests wie TRAP (,total peroxyl radical-trapping antioxidant parameter"), ORAC („oxygen radical absorbance capacity“), TEAC („trolox equivalent antioxidant capacity“), FRAP („ferric ion reducing antioxidant power") oder PCL (Bestimmung der antioxidativen Kapazität mittels Photochemilumineszenz) eingesetzt $[93,94]$, die im Folgenden kurz dargestellt werden sollen.

Alle Tests fallen in eine von 2 Kategorien (• Abb. 2): Zum einen wird untersucht, wie effektiv eine Probe die durch ein im Testsystem eingesetztes Oxidans verursachte Oxidation einer Sonde verhindert. Messparameter sind dabei oft Absorptions- oder Fluoreszenzeigenschaften der Sonde, die sich mit ihrem Oxidationsstatus ändern (vgl. • Abb. 2, Teil A; dies trifft auf die unten beschriebenen TRAP und ORAC sowie im Prinzip auf PCL zu). Zweitens kann analysiert werden, wie effektiv eine Probe selbst eine
Sonde zu reduzieren vermag. Als Messparameter dient, wie zuvor, eine reduktive Veränderung spektrophotometrischer Eigenschaften der Sonde (• Abb. 2, Teil B; dies trifft auf TEAC und FRAP zu).

TRAP, ORAC sowie Modifikationen. In diesen Tests wird untersucht, wie effektiv eine Probe eine fluoreszierende Redoxsonde, wie z. B. Fluoreszeinderivate, RPhycoerythrin oder DIPY 665/676, vor der Oxidation durch hydro- oder lipophile Peroxylradikale [im Ansatz durch Zerfall der thermolabilen Verbindungen 2,2'-Azobis(2-amidinopropan), AAPH bzw. 2,2'-Azobis(2,4-dimethylvaleronitril), AMVN, erzeugt] schützen kann.

TEAC. Durch Persulfat wird die Oxidation von 2,2'-Azinobis(3-ethylbenzothiazolin6-sulfonat) ( $\mathrm{ABTS}^{2-}$ ) initiiert und das ABTS $^{\bullet}$--Radikal gebildet. Analysiert wird die Fähigkeit einer Probe, das ABTS •Radikal zu reduzieren. Als Standard wird hierbei eine 1-mM-Lösung des wasserlöslichen synthetischen Vitamin-E-Analogons Trolox eingesetzt und die antioxidative Aktivität der untersuchten Probe in Trolox-Äquivalenten ausgedrückt.

FRAP. In diesem Test wird die Fähigkeit einer Probe untersucht, $\mathrm{Fe}$ (III) $\mathrm{Cl}_{3}$ (TPTZ) (TPTZ: 2,4,6-Tripyridyltriazin) zu Fe(II) $\mathrm{Cl}_{2}$ (TPTZ) $)_{2}$ zu reduzieren.

\section{PCL (Bestimmung der antioxidativen Ka- pazität mittels Photochemilumines-} zenz). In diesem Testsystem wird das Superoxidanionradikal erzeugt und mithilfe von Chemilumineszenzverfahren detektiert. Durch Bestrahlung einer Luminolhaltigen Lösung mit UV-A-Strahlung wird photochemisch das Superoxidanionradikal gebildet, das gleichzeitig wiederum das Luminol oxidiert. Diese Oxidation geht mit der Emission von Photonen einher, die chemiluminometrisch detek- 
tiert werden. Messparameter ist die Fähigkeit einer Probe, das Chemilumineszenzsignal zu unterdrücken bzw. das Superoxidanionradikal abzufangen [94].

\section{Bewertung von Tests zur Analyse der gesamten antioxidativen Kapazität}

Die oben beschriebenen Testsysteme werden in wissenschaftlichen Arbeiten häufig eingesetzt, um die Änderungen der antioxidativen Aktivität im Plasma nach einer Intervention mit Lebensmitteln oder mit chemisch sehr komplexen (oft pflanzlichen) Extrakten, die eine Vielzahl von Substanzen mit antioxidativen Eigenschaften enthalten, zu untersuchen.

Diese Methoden mögen eine Möglichkeit der ersten Abschätzung hinsichtlich einer potenziell erzielten Wirkung auf den Redoxstatus des Plasmas oder die Änderung der Fähigkeit des untersuchten Systems, bestimmte reaktive Moleküle zu inaktivieren, bieten. Sie geben jedoch keinerlei Information darüber, wie relevant eine solche Änderung der antioxidativen Kapazität für die Prävention oxidativer Schädigung im Körper ist. Sie lassen weiterhin keine spezifische Aussage zu, die konkrete Angaben zu tatsächlich veränderten Antioxidantienspiegeln, die die identifizierten Änderungen der antioxidativen Kapazität bedingen, erlaubten. Wie bereits dargestellt, sind in biologischen Proben wie Plasma zahlreiche verschiedene Substanzen enthalten, die je eigene Anteile an der Inaktivierung der im Testsystem untersuchten reaktiven Spezies haben. Der weitaus größte Teil der in solchen Tests analysierten antioxidativen Kapazität des Blutplasmas geht jedoch nur auf wenige Bestandteile zurück: Plasmaproteine (v. a. Albumin), Harnsäure/Urat, Vitamin C/Ascorbat sowie Tocopherol [95]. Mit der Analyse der gesamten antioxidativen Kapazität des Plasmas wird demnach im Prinzip eine Abschätzung der Konzentration dieser Verbindungen durchgeführt. Diese Substanzen sind allerdings analytisch recht gut zugänglich, sodass die Analyse ihrer Konzentrationen meist einer Bestimmung der gesamten antioxidativen Kapazität vorzuziehen ist.

Tests zur Abschätzung der gesamten antioxidativen Kapazität erwecken oft den falschen Eindruck, dass sich die Abwehrbereitschaft gegen alle unterschiedlichen reaktiven Spezies gleichermaßen bestimmen ließe. Tatsächlich wird lediglich die Fähigkeit einer Probe analysiert, ein bestimmtes im jeweiligen Test eingesetztes reaktives Molekül - das zudem oftmals ohne biologische oder pathologische Relevanz ist - zu neutralisieren.

Weiterhin erfassen die dargestellten Tests keinesfalls stets die „gesamte“ antioxidative Kapazität einer Probe, etwa eines Gewebehomogenats, denn der für das antioxidative Netzwerk essenzielle Anteil enzymatischer antioxidativer Reaktionen, darunter auch enzymatische Reparaturmechanismen, wird nicht erfasst [26, 95].

Schließlich werden Messwerte zur gesamten antioxidativen Kapazität auch umgekehrt durch einige pathologische und physiologische Zustände, die mit oxidativem Stress in keiner offensichtlichen Verbindung stehen, beeinflusst [96], was sich etwa für Untersuchungen an Blutplasma zwanglos aus der oben erwähnten Beobachtung ergibt, dass beispielsweise Proteine und Harnsäure einen Großteil der Oxidansabwehr übernehmen. Für Tests zur gesamten antioxidativen Kapazität fehlen internationale Validierung und pathobiochemische Relevanz.

\section{Bedeutung und Interpretation erhöhter Konzentrationen von Biomarkern des oxidativen Stresses und/oder erniedrigter Antioxidantienkonzentrationen}

Eine vermehrte oxidative Schädigung biologischer Moleküle ist das Resultat einer Verschiebung des Gleichgewichts zwischen Pro- und Antioxidantien zugunsten der Ersteren, also das Produkt eines „oxidativen Stresses“. In diesem Sinne ist auch eine Erhöhung der Konzentrationen der als Indikatormoleküle angesehenen Oxidationsprodukte in einem untersuchten System zu interpretieren. Die Auslenkung des Gleichgewichtes kann hierbei durch vermehrte Bildung von ROS/RNS oder aber durch Absenken der antioxidativen Kapazität des Systems verursacht worden sein.

Messwerte, die für Plasma- oder Urinproben gewonnen wurden, lassen keine
Rückschlüsse hinsichtlich der Herkunft der Indikator-/Markermoleküle zu: Es bleibt unklar, welches Organ oder Gewebe von oxidativem Stress betroffen ist. Es bleibt weiterhin unklar, welche reaktive Spezies die oxidative Schädigung initiiert hat oder welches Antioxidans im Körper in zu geringen Konzentrationen vorliegt. Oft sind erhöhte Messwerte für Marker des oxidativen Stresses mit degenerativen, akuten oder chronischen entzündungsbegleitenden Erkrankungen verbunden (• Tabelle 2 und 6); in solchen Fällen ist die Krankheit direkt zu behandeln, also eine wie auch immer geartete „antioxidative Therapie" (oft in Form von Antioxidans-Supplementation) nicht zu bevorzugen [23, 97].

Sollten hingegen erhöhte Messwerte für Marker des oxidativen Stresses nicht mit erkennbaren Krankheitszeichen einhergehen, so kann das antioxidative System des menschlichen Körpers näher betrachtet werden. Wie oben beschrieben, existiert ein Netzwerk antioxidativ wirkender Moleküle, das aus Enzymen (wie Katalase, Superoxiddismutasen und Glutathionperoxidasen) besteht, die spezifisch bestimmte reaktive Sauerstoff- und Stickstoffspezies inaktivieren können, sowie einer Vielzahl niedermolekularer exogener und endogener Substanzen, die ebenfalls zur Erhaltung der antioxidativen Kapazität beitragen [96]. In • Tabelle 7 sind einige bekannte Antioxidantien und ihre Wirkspektren gegenüber spezifischen ROS/RNS aufgelistet. Dabei wird deutlich, dass ein Antioxidans nicht alle ROS/RNS gleichermaßen effektiv zu inaktivieren vermag, sondern dass eine Vielzahl an Antioxidantien für die antioxidative $\mathrm{Ba}$ lance notwendig ist. Weiterhin muss beachtet werden, dass die Konzentrationen von prooxidativ und antioxidativ wirkenden Substanzen im menschlichen Körper sehr heterogen verteilt sind und stark von Organ zu Organ, Gewebe zu Gewebe oder von einer intrazellulären Struktur zur anderen variieren. Auch wenn ein Antioxidans eine ROS/RNS in einer homogenen Lösung sehr effektiv inaktivieren kann, bedeutet dies nicht, dass die Konzentration dieses Antioxidans überall im Körper ausreicht, um die körpereigenen Biomoleküle vor ROS/RNS zu schützen. 


\section{Empfehlung des Robert Koch-Instituts}

Tabelle 6

\section{Einige Erkrankungen, die mit erhöhtem MDA-Plasmaspiegeln assoziiert} sind

\begin{tabular}{lll}
\hline Zustand/Erkrankung & $\begin{array}{l}\text { MDA }(\mu \mathrm{M}) \\
\text { Zustand oder Erkrankung vs. Kontrollgruppe } \\
\text { Methode }\end{array}$ & Literatur \\
\hline Chronische Hepatitis C & $\begin{array}{l}1,53 \pm 0,53 \text { vs. } 0,55 \pm 0,17(\mathrm{P}<0,001) \\
\text { HPLC }\end{array}$ & Ref. [142] \\
\hline Koronare Herzerkrankung & $\begin{array}{l}2,6 \text { vs. } 1,3(P<0,00001) \\
\text { GC-MS }\end{array}$ & Ref. [151] \\
\hline B-Thalassämie & $\begin{array}{l}1,22 \text { vs. } 0,37 \pm 0,25 \\
\text { HPLC }\end{array}$ & Ref. [152] \\
\hline $\begin{array}{l}\text { Stenokardie } \\
\text { (instabile, anhaltende) }\end{array}$ & $\begin{array}{l}2,85 \text { u. } 2,45 \text { vs. 1,43 } \\
\text { GC-MS }\end{array}$ & Ref. [153] \\
\hline Rauchen & $\begin{array}{l}0,66 \text { vs. } 0,60(p<0,05) \\
\text { HPLC }\end{array}$ & Ref. [134] \\
\hline Diabetes & 0,43 vs. 0,38 & Ref. [154] \\
\hline Chronische & HPLC & Ref. [155] \\
\hline Nierenerkrankungen & $\begin{array}{l}1,10 \text { vs. } 0,69 \\
\text { HPLC }\end{array}$ & \\
\hline
\end{tabular}

Tabelle 7

Relative Spezifität der antioxidativen Aktivität einiger ausgewählter Antioxidantien

\begin{tabular}{|c|c|c|c|c|c|c|}
\hline & $\mathrm{O}_{2}^{\bullet-}$ & $\mathrm{H}_{2} \mathrm{O}_{2}$ & LOO & LOOH & $\mathrm{ONOO}^{-}$ & ${ }^{1} \mathrm{O}_{2}$ \\
\hline \multicolumn{7}{|c|}{ Lipidlösliche Antioxidantien } \\
\hline a-Tocopherol (Vit. E) & + & & +++ & & + & ++ \\
\hline$\beta$-Carotin (Provit. A) & & & ++ & & + & +++ \\
\hline Coenzym Q10 & & & +++ & & & + \\
\hline Lycopin & & & ++ & & + & +++ \\
\hline \multicolumn{7}{|c|}{ Wasserlösliche Antioxidantien } \\
\hline Ascorbinsäure & ++ & & ++ & & + & ++ \\
\hline $\begin{array}{l}\text { Thiole, z. B. Glutathion, } \\
\text { N-Acetylcystein }\end{array}$ & & + & ++ & & +++ & ++ \\
\hline Flavonoide, z. B. Rutin & ++ & & ++ & & ++ & + \\
\hline \multicolumn{7}{|l|}{ Enzyme } \\
\hline Superoxiddismutase & +++ & & & & & \\
\hline Katalase & & +++ & & & & \\
\hline Glutathionperoxidasen & & +++ & & +++ & +++ & \\
\hline
\end{tabular}

$\mathrm{O}_{2}{ }^{\bullet}$ - Superoxidanionradikal; $\mathrm{H}_{2} \mathrm{O}_{2}$ Wasserstoffperoxid; LOO Peroxylradikal; $\mathrm{LOOH}$ Lipidhydroperoxid; $\mathrm{ONOO}^{-}$Peroxynitrit; ${ }^{1} \mathrm{O}_{2}$ Singulettsauerstoff; + antioxidative Aktivität; ++ ausgeprägte antioxidative Aktivität; +++ sehr ausgeprägte antioxidative Aktivität (für die Abschätzung der Aktivität wurden die Reaktionsgeschwindigkeitskonstante und typische physiologische Konzentration des Antioxidans berücksichtigt)

Die am besten untersuchten niedermolekularen, antioxidativ wirksamen Substanzen sind Ascorbinsäure, Tocopherole, Carotinoide und das Spurenelement
Selen, das in Form der Aminosäure Selenocystein essenzieller Bestandteil endogen antioxidativ wirkender Selenoproteine ist, beispielsweise der Glutathionper- oxidasen oder des Selenoproteins P. Neben der antioxidativen Wirkung sind für diese Verbindungen auch zahlreiche andere biologische Aktivitäten und mögliche $\mathrm{Ne}$ benwirkungen bekannt. Die optimalen Plasmakonzentrationen, empfohlene tägliche Zufuhr, obere tägliche Zufuhrmenge ohne unerwünschte Wirkungen sowie mit bekannten Nebenwirkungen von $\alpha$-Tocopherol, $\beta$-Carotin, Ascorbinsäure und einigen anderen Antioxidantien sind in - Tabelle 1b aufgeführt. Bezüglich Selen wird auf die Stellungnahme der RKIKommission verwiesen [98] und zur Anwendung von Antioxidantien im Rahmen der Prävention auf die Übersichtsarbeit in Ref. [99].

Für Nahrungsergänzungsmittel gilt, dass eine zusätzliche Zufuhr dieser Substanzen selten zur weiteren Minderung oxidativer Schäden führt, wenn die Plasmakonzentrationen der Nahrungsantioxidantien im optimalen Bereich liegen $[14,100,101,102]$, und nur bei Mangelzuständen einen positiven Effekt ergibt. Im Falle der ausreichenden Versorgung mit Nahrungsantioxidantien ist es wichtig, andere Faktoren, die zur verstärkten Produktion von Prooxidantien führen, $\mathrm{zu}$ identifizieren (Erkrankungen, Rauchen, Alkoholkonsum, metabolisches Syndrom, erhöhte Exposition gegenüber UV, Ozon, Stäuben usw.) und zu bekämpfen.

Viele antioxidativ wirkende Substanzen, wie etwa Selen, Vitamin A, $\alpha$-Tocopherol oder $\beta$-Carotin, besitzen außerdem weitere biologische Wirkungen, die bei Überversorgung zu unerwünschten Wirkungen führen können. So erhöht beispielsweise die Supplementation mit $\beta$-Carotin in isolierter Form (>20 mg/ Tag) die Mortalität an Lungenkrebs für verschiedene Risikogruppen (z. B. starke Raucher, Personen mit erhöhtem Alkoholkonsum, Arbeiter mit Asbestexposition). Auch eine kürzlich veröffentlichte Metaanalyse, die ca. 50 Studien analysiert hat, zeigte, dass zwar die Supplementierung mit Vitamin $\mathrm{C}$ und Selen die Sterblichkeitsrate nicht beeinflusste, diese jedoch durch Supplementierung mit $\beta$ Carotin um $6 \%$, bei Vitamin A um $16 \%$ und bei Vitamin E um $4 \%$ erhöht war [103].

Einige ROS/RNS, z. B. Stickstoffmonoxid, Wasserstoffperoxid oder Singulettsau- 
Tabelle 8

Reduktion des oxidativen Stresses durch Ernährung und gesundheitsbewusstes Verhalten

Empfehlungen

Mehr Obst und Gemüse

Täglich 5 Portionen Gemüse und Obst, mindestens $650 \mathrm{~g}$

Weniger rotes Fleisch

Ein- bis zweimal in der Woche Fleisch, Wurstwaren (300-600 g Fleisch und Wurst pro Woche)

\section{Weniger Fett}

Insgesamt 60-80 Gramm Fett pro Tag, fettarme Produkte, vor allem bei

Fleischerzeugnissen und Milchprodukten

Weniger Zucker

Zucker und Lebensmittel bzw. Getränke, die mit verschiedenen Zuckerarten (z. B. Glucosesirup) hergestellt wurden, sollen nur gelegentlich verzehrt werden

\section{Wenig Alkohol}

Für den gesunden Mann wird eine Zufuhr von $20 \mathrm{~g}$ Alkohol pro Tag als gesundheitlich verträglich angegeben, für die gesunde Frau $10 \mathrm{~g}$ Alkohol

Nicht Rauchen

Moderate körperliche Aktivität (mindestens $30 \mathrm{~min} / \mathrm{Tag}$ )

\section{Kommentar}

Obst und Gemüse liefern pflanzliche Antioxidantien (Vitamin C, Carotinoide, Polyphenole), haben eine niedrige Energiedichte und dadurch niedrige oxidative Belastung durch postprandiale Hyperglykämie und Hypertriglyzeridämie

„Rotes“ Fleisch oder Fleischwaren haben im Durchschnitt einen hohen Eisengehalt. Eine zu hohe Eisenzufuhr wirkt prooxidativ. Tierische Fette führen zu oxidativem Stress durch postprandiale Hypertriglyzeridämie

Postprandiale Hypertriglyzeridämie fördert oxidative Prozesse

Der hohe glykämische Index von Zucker führt zur postprandialen Hyperglykämie und zur oxidativen Schädigung

Alkohol induziert oxidative Schäden vor allem in der Leber

Tabakrauch enthält eine Vielzahl von Substanzen, die direkt oder indirekt oxidative Prozesse im Organismus initiieren

Körperliche Aktivität stimuliert endogene antioxidative Enzyme und führt zu niedrigerer Bildung von ROS/RNS in Mitochondrien erstoff, sind darüber hinaus wichtige endogene Mediatoren biologischer Prozesse. Eine völlige Unterdrückung der Bildung/ Spiegel von ROS/RNS sollte demnach vermieden und aus diesem Grunde auch auf die sogenannten „Megadosen“ von Antioxidantien verzichtet werden. Da bis jetzt nicht geklärt ist, ob und welche ROS/RNS in welcher Konzentration und durch Eingriff in welche Regelkreise eine entscheidende Rolle bei Entstehung und Verlauf der mit oxidativem Stress assoziierten Krankheiten spielen, sollte im Bezug auf eine „antioxidative Behandlung“ der Sicherheitsaspekt im Vordergrund stehen [104]. Dabei sollten wenig untersuchte antioxidativ wirksame Extrakte/Verbindungen nicht angewendet werden. Die Empfehlung des Hohenheimer Konsensusgesprächs [105] ist nach Auffassung der Kommission weiterhin gültig und wird deshalb an dieser Stelle noch einmal aufgeführt:

„... die Korrektur einer suboptimalen Antioxidantienzufuhr bei Gesunden wie auch bei Risikopatienten stellt nur dann eine echte präventive Maßnahme dar, wenn gleichzeitig eine Minderung der prooxidativen Risikofaktoren verwirklicht wird“.

Derzeit kann kein spezifisches Antioxidans oder eine definierte Mischung bekannter Antioxidantien identifiziert werden, welches bzw. welche die Schwäche des ganzen Antioxidantien-Netzwerkes auf Dauer kompensieren könnte [106]. Deshalb geht die aktuelle Empfehlung der Deutschen Gesellschaft für Ernährung (DGE) zur Prävention von HerzKreislauf- und Krebserkrankungen mit der Empfehlung zur Reduktion des Risikos für oxidativen Stress über eine vollwertige Ernährung mit mehr Gemüse, Obst und Vollkornprodukten, fettarmen Varianten von Milch und Milchprodukten, weniger Fleisch sowie Fleischwaren und wenig Alkohol einher.

Die DGE empfiehlt täglich 5 Portionen Gemüse und Obst, mindestens $650 \mathrm{~g}$ täglich, reichlich Vollkornprodukte, ein- bis zweimal in der Woche Fisch sowie 300$600 \mathrm{~g}$ Fleisch und Wurst pro Woche. Fettarme Produkte, vor allem bei Fleischerzeugnissen und Milchprodukten, sind zu bevorzugen, ebenso pflanzliche Öle und Fette statt tierischer Fette (insgesamt 6o$80 \mathrm{~g}$ Fett pro Tag). Zucker und Lebensmittel bzw. Getränke, die mit verschiedenen Zuckerarten (z. B. Glucosesirup) hergestellt wurden, sollen nur gelegentlich verzehrt werden. Der Bezug dieser Empfehlungen zu oxidativem Stress ist in $\bullet \mathrm{Ta}$ belle 8 dargelegt. Eine solche ausgewogene Ernährung führt bei jüngeren Erwachsenen in der Regel zu einer ausreichenden Zufuhr antioxidativ wirksamer Vitamine und Wirkstoffe. Jedoch ernähren sich ältere Menschen oft nicht optimal und weisen zum Teil Mangelzustände auf [107].

\section{Zur Frage der Diagnostik des Antioxidantienstatus bei Umweltbelastungen}

Zahlreiche Untersuchungen weisen darauf hin, dass eine Exposition gegenüber unterschiedlichen Noxen am Arbeitsplatz und in der Umwelt zu erhöhtem oxidativem Stress im Organismus führt, der mit Biomarkern des oxidativen Stresses nachgewiesen werden kann $[4,6,51$, 
$108,109]$. Ein häufig verwendeter Biomarker stellt dabei 8-oxo-dG dar, entweder als Messung in Lymphozyten-DNA oder als im Urin ausgeschiedene Menge. So kann ein Einfluss auf diesen Biomarker durch Tabakrauchen und Belastungen am Arbeitsplatz mit Asbest, polyzyklischen aromatischen Kohlenwasserstoffen (PAK), Benzol, Styrol, Flugasche und Schweißrauch im Gruppenvergleich als meist statistisch signifikant angesehen werden. Auch für Umweltbelastungen, wie Arsen im Trinkwasser, allgemeine Verkehrsemissionen, Ozon und $\mathrm{PM}_{2,5}$ und PM1o wurde ein signifikanter $\mathrm{Zu}$ sammenhang zwischen Exposition und 8-oxo-dG sowie bei Frauen und Kindern möglicherweise auch für MDA beschrieben. In einer Arbeit wurde ein Zusammenhang für 8-oxo-dG mit dem SickBuilding-Syndrom und erhöhten Gehalten von flüchtigen organischen Verbindungen (VOC) und $\mathrm{CO}_{2}$ in der Innenraumluft gefunden [110], was mit Befunden von zum Winkel [7] in Übereinstimmung ist, der bei Patienten einer umweltmedizinischen Praxis im Vergleich zu Kontrollen erniedrigte Werte für die SOD und eine Tendenz für erniedrigte Glutathiongehalte und erhöhtes MDA im Plasma fand. Für die sogenannten umweltmedizinischen Syndrome (MCS/IEI) [2], CFS [111, 112] und Fibromyalgie [113] wurden mögliche Zusammenhänge mit oxidativem Stress postuliert, aber die wirkliche Bedeutung ist bisher unklar. Eine Untersuchung zur Elektrosensibilität konnte keine Unterschiede hinsichtlich des oxidativen Status zu Gesunden und keine Wirkung durch Gabe von Antioxidantien feststellen [114]. Während für zahlreiche arbeitsplatzbezogene Wirkungen ein Zusammenhang als gut belegt angesehen werden kann [4], ist die Datenlage für die Umweltmedizin als unzureichend anzusehen. Da sich aber bereits bei üblichen Hintergrundbelastungen durch den StraBenverkehr und städtische Luftverschmutzung (Feinstaub) Wirkungen auf bestimmte Parameter des oxidativen Stresses zeigen, wären Untersuchungen bei entsprechenden umweltmedizinischen Fragestellungen an Kollektiven begründbar und sinnvoll. Für den einzelnen Patienten ist die Interpretation je- doch erheblich eingeschränkt, da es sich nicht um spezifische Parameter handelt. Der Parameter 8-oxo-dG im Urin korreliert auch nicht mit 8-oxo-dG in der DNA, sodass bei verminderter DNAReparaturkapazität trotz erhöhtem oxidativem Stress keine auffälligen Urinwerte auftreten [115]. Es besteht zudem eine erhebliche intra- und interindividuelle Varianz. Neben genetisch determinierten Polymorphismen der Glutathion-S-Transferase (GSTM) und der Apurin/Apyrimidin Endonuclease (APE) sind als Confounder verschiedene Erkrankungen, Geschlecht, körperliche Aktivität, Alter, Ernährung, Rauchen, Rotwein und auch Einnahme von Supplementen/Vitaminen zu nennen [65, $107,114,116,117,118,119]$.

\section{Qualitätssicherung}

Die qualitative Wertigkeit des Testes ist abhängig von der Validierung und dem Qualitätsbewusstsein im durchführenden Labor. Wie schon dargelegt, gibt es sehr viele methodische Varianten, die einen Einfluss auf das Ergebnis haben können.

Das Labor ist verpflichtet, die Richtlinien der Bundesärztekammer (RiLiBÄK) in der aktuellen Fassung oder alternativ die Festlegung der entsprechenden Normen (vor allem DIN/EN/ISO 17025 oder 15189) einzuhalten [120].

\section{Bewertung und Empfehlungen}

Pathophysiologische Relevanz des Markers, adäquate Messmethode und Probenmaterial sind wichtige Faktoren für die Auswahl diagnostischer Marker des oxidativen Stresses. Als die derzeit am besten geeigneten Marker/Messmethoden zur Erfassung eines oxidativen Stresses beim Menschen im Zusammenhang mit umweltmedizinischen Fragestellungen werden (i) die Analyse der oxidativen Nukleinsäureschädigung durch Bestimmung von 8-Oxo-7,8-dihydro-2'-(desoxy)guanosin in Urinproben mithilfe von GC-MS oder HPLC-MS, (ii) die Analyse der Lipidoxidation durch Bestimmung von 8-Isoprostan in Urin/Plasma per GC-MS, von Malondialdehyd in Urin/Plasma mit HPLC, GC-MS, (iii) die Analyse des Antioxidantienstatus durch Bestimmung der
Plasmakonzentrationen von Vitamin C und $\mathrm{E}$ angesehen. Sinnvollerweise sollten dabei verschiedene Assays miteinander kombiniert werden $[26,121,122,123]$. Wiederholungsmessungen zur Absicherung oder zur Verlaufskontrolle sind sinnvoll [23]. Laborverfahren sollten nach den internen Qualitätsrichtlinien der Bundesärztekammer (RiLiBÄK) überprüft und qualitätsgesichert werden [120].

Da die molekularen Mechanismen und die Rolle der ROS/RNS bei der Entstehung und Entwicklung von mit ROS/RNS assoziierten Erkrankungen nicht endgültig geklärt sind, ist die Durchführung von diagnostischen Maßnahmen mit umweltmedizinischer Indikation allerdings nur unter Vorbehalten zu empfehlen.

Supplementierung mit Selen oder den antioxidativ wirkenden Vitaminen $C$ und $\mathrm{E}$ ist nur bei nachgewiesenen Mangelzuständen und nach einer fehlgeschlagenen Ernährungsumstellung angebracht. Für eine gezielte Therapie mit Antioxidantien bei bestimmten akuten und chronischen Krankheiten und besonderen Beanspruchungen sind bislang keine ausreichend validierten Empfehlungen vorhanden. Unkontrollierte und nicht begründete Supplementierung mit Antioxidantien, wie $\beta$-Carotin oder Vitamin E ( $\alpha$-Tocopherol), sind nicht zu empfehlen, da sie unter bestimmten Umständen die Lebenserwartung verkürzen [124].

Die Intensität, mit der Forschung auf dem Gebiet des oxidativen Stresses betrieben wird, lässt vermuten, dass in den nächsten Jahren bestehende und neue Methoden nach erfolgreicher (pathophysiologischer und analytischer) Validierung und analytischer Qualitätssicherung in das diagnostische Repertoire aufgenommen werden können. Mit dieser Thematik befasst sich zurzeit eine Arbeitsgruppe der Deutschen Gesellschaft für klinische Chemie.

\section{Einstufung durch die RKI-Kommission}

Die Einstufung erfolgt auf Basis des Einstufungsschemas der Kommission [125].

Für eine kollektive umweltmedizinische Indikation, in der eine Gruppe von Exponierten und eine entsprechende Kontrollgruppe untersucht werden, sind 
folgende Parameter der Kategorie I B zuzuordnen (Zitat: Eine Maßnahme kann bei gegebener umweltmedizinischer Indikation empfohlen werden):

- 8-Oxo-7,8-dihydro-2'-(desoxy)guanosin in Urin,

- Isoprostan in Urin/Plasma,

- Malondialdehyd in Urin/Plasma,

- Vitamin C und E in Plasma.

Für eine individualmedizinische umweltmedizinische Indikation sind die folgenden Parameter der Kategorie II zuzuordnen (Zitat: Eine Maßnahme kann bei gegebener umweltmedizinischer Indikation unter Vorbehalten empfohlen werden):

Vitamin C und $\mathrm{E}$ in Plasma.

Für eine individualmedizinische umweltmedizinische Indikation sind die Parameter 8-Oxo-7,8-dihydro-2'-(desoxy)guanosin/Urin, Isoprostan in Urin/Plasma, Malondialdehyd in Urin/Plasma der Kategorie III zuzuordnen (Zitat: Eine Maßnahme kann nicht empfohlen werden, weil kein ausreichendes Erfahrungsmaterial vorliegt und theoretische Überlegungen nicht für eine Wirksamkeit sprechen).

Alle anderen Marker des oxidativen Stresses (siehe $\bullet$ Tabelle $4 a-d$ ) sind derzeit der Kategorie IV zuzuordnen (Zitat: Eine Maßnahme kann nicht empfohlen werden, weil kein ausreichendes Untersuchungsmaterial vorliegt und theoretische Überlegungen nicht für eine Wirksamkeit sprechen).

\section{Federführung}

Priv. Doz. Dr. med. Karlis Briviba (externer Sachverständiger), Institut für Ernährungsphysiologie, Bundesforschungsanstalt für Ernährung, Haid-und-Neu-Str. 9, 76131 Karlsruhe; Dr. med. Birger Heinzow, Landesamt für soziale Dienste, Umweltbezogener Gesundheitsschutz, Brunswikerstr. 4, 24105 Kiel; Prof. Dr. rer. nat. M. Schwenk (Tübingen)

\section{Externe Sachverständige}

Priv. Doz. Dr. rer. nat. Lars-Oliver Klotz, Institut für umweltmedizinische Forschung an der Heinrich-Heine-Universität Düsseldorf gGmbH, Auf'm Hennekamp 50, 40225 Düsseldorf; Dr. med. Diethard Müller, Labor Dr. Gärtner, Elisabethen- straße 11, 88212 Ravensburg; Dr. rer. nat. Corinna Rüfer, Institut für Ernährungsphysiologie, Bundesforschungsanstalt für Ernährung, Haid-und-Neu-Str. 9, 76131 Karlsruhe

\section{Kommissionsmitglieder}

Dr. A. Beyer (Umweltmed. Ambulanz Berlin-Steglitz/Zehlendorf), Prof. Dr. W. Dott (Universitätsklinikum Aachen, Institut für Hygiene und Umweltmedizin), Prof. Dr. H. Drexler (Friedrich- Alexander-Universität Erlangen-Nürnberg, Institut für Arbeits-, Sozial- und Umweltmedizin), Prof. Dr. H. Dunkelberg (Universität Göttingen, Abt. Allg. Hygiene u. Umweltmedizin), Prof. Dr. Th. Eikmann (Universität Gießen, Institut f. Hygiene u. Umweltmedizin), Dr. B. Heinzow (Landesamt für soziale Dienste Schleswig-Holstein, Dezernat Umweltbezogener Gesundheitsschutz, Kiel), Prof. Dr. C. Hornberg (Universität Bielefeld, Fakultät für Gesundheitswissenschaften), Prof. Dr. Dr. A.D. Kappos (Frankfurt/Main), Prof. Dr. K.E. von Mühlendahl (Kinderhospital Osnabrück, Gemeinnützige Kinderumwelt GmbH), Prof. Dr. D. Nowak (LMU München, Klinikum Innenstadt, Institut u. Poliklinik für Arbeits- und Umweltmedizin), PD Dr. F.-A. Pitten (Institut für Krankenhaushygiene und Infektionskontrolle GbR, Gießen), Dr. W. Stück (Ökologischer Ärztebund/ISDE, Koblenz), Prof. Dr. M. Schwenk (Tübingen), Dr. R. Suchenwirth (Niedersächsisches Landesgesundheitsamt, Abt. Umweltmedizin/Epidemiologie, Hannover), Prof. Dr. M. Wilhelm (Universität Bochum, Hygiene, Sozialund Umweltmedizin).

\section{Ständige Gäste}

Dr. N. Englert (Umweltbundesamt, Berlin), Dr. A. Hahn (Bundesinstitut für Risikobewertung, Berlin), Dr. U. Winkler (Bundesministerium für Gesundheit, Referat 332).

\section{Geschäftsstelle im RKI}

Dr. D. Eis, Dr. U. Wolf.

\section{Literatur}

1. Schröder P, Krutmann J (2005) Environmental oxidative stress. Springer, Berlin, Heidelberg

2. Bieger WP, Bartram F, Knabenschuh B, et al. (2002) Die Rolle von oxidativem Stress in der Pathogenese von MCS. Z Umweltmed 10:198-205

3. Bartram F (2005) Immuninduzierte Entzündungsprozesse durch chronische Chemikalienbelastung. Umwelt-Medizin-Gesellschaft 18:202-208

4. Pilger A, Rudiger HW (2006) 8-Hydroxy-2'-deoxyguanosine as a marker of oxidative DNA damage related to occupational and environmental exposures. Int Arch Occup Environ Health 80:1-15

5. Bräuner EV, Forchhammer L, Moller P, et al. (2007) Exposure to ultrafine particles from ambient air and oxidative stress-induced DNA damage. Environ Health Perspectives 115:1177-1182

6. Moller P, Folkmann JK, Forchhammer L, etal. (2008) Air pollution, oxidative damage to DNA and carcinogenesis. Cancer Letters 266:84-97

7. zum Winkel A, Fenner T, Köster HD (2004) Oxidativer Stress in der Umweltmedizin. Umwelt-Medizin-Gesellschaft 17:238-243

8. Sies H (1991) Oxidative stress: from basic research to clinical application. Am J Med 91:31S-38S

9. Sies H (1997) Oxidative stress: oxidants and antioxidants. Experimental Physiol 82:291-295

10. Sies H (2007) Biological redox systems and oxidative stress. Cell Mol Life Sci 64:2181-2188

11. Grune T (2005) Handbook of environmental chemistry, Vol. 2. Springer, Berlin, Heidelberg

12. Ryter SW, Kim HP, Hoetzel A, et al. (2007) Mechanisms of cell death in oxidative stress. Antioxidants Redox Signaling 9:49-89

13. Orrenius S, Gogvadze V, Zhivotovsky B (2007) Mitochondrial oxidative stress: implications for cell death. Annual Rev Pharmacol Toxicol 47:143-183

14. Mishra V (2007) Oxidative stress and role of antioxidant supplementation in critical illness. Clin Lab 53:199-209

15. Kregel KC, Zhang HJ (2007) An integrated view of oxidative stress in aging: basic mechanisms, functional effects, and pathological considerations. Am J Physiol 292:R18-R36

16. Lastra G, Manrique C (2007) The expanding role of oxidative stress, renin angiotensin system, and beta-cell dysfunction in the cardiometabolic syndrome and Type 2 diabetes mellitus. Antioxidants Redox Signaling 9:943-954

17. Maiese K, Chong ZZ, Shang YC (2007) Mechanistic insights into diabetes mellitus and oxidative stress. Curr Med Chem 14:1729-1738

18. Sies H (1991) Oxidative stress: oxidants and antioxidants. Academic Press, London

19. Ovechkin AV, Lominadze D, Sedoris KC, et al. (2007) Lung ischemia-reperfusion injury: implications of oxidative stress and platelet-arteriolar wall interactions. Arch Physiol Biochem 113:1-12

20. Sies H (1997) Antioxidants in disease mechanisms and therapy. Academic Press, San Diego

21. Cutler RG, Plummer J, Chowdhury K, Heward C (2005) Oxidative stress profiling: part II. Theory, technology, and practice. Ann N.Y. Acad Sci 1055: 136-158

22. Halliwell B, Gutteridge JMC (2007) Free radicals in biology and medicine. Oxford University Press, New York

23. Tsukahara $\mathrm{H}$ (2007) Biomarkers for oxidative stress: clinical application in pediatric medicine. Curr Med Chem 14:339-351

24. Halliwell B (2007) Oxidative stress and cancer: have we moved forward? Biochem J 401:1-11 
25. Halliwell B (2006) Oxidative stress and neurodegeneration: where are we now? J Neurochem 97:1634-1658

26. Breusing N, Grune T (2008) Analytik von oxidativem Stress - was ist gesichert? Aktuel Ernähr Med 33:106-115

27. Kappus H (1987) Oxidative stress in chemical toxicity. Arch Toxicol 60:144-149

28. Li GJ, Zhang LL, Lu L, etal. (2004) Occupational exposure to welding fume among welders: alterations of manganese, iron, zinc, copper, and lead in body fluids and the oxidative stress status. J Occup Environ Med 46:241-248

29. Gokirmak M, Yildirim Z, Canan Hasanoglu H, etal. (2003) The role of oxidative stress in bronchoconstriction due to occupational sulfur dioxide exposure. Clinica chimica acta 331:119-126

30. Flore R, Gerardino L, Santoliquido A, et al. (2004) Enhanced oxidative stress in workers with a standing occupation. Occup Environ Med 61:548-550

31. Turkan H, Aydin A, Sayal A (2005) Effect of volatile anesthetics on oxidative stress due to occupational exposure. World J Surg 29:540-542

32. Lösch M, Bieger WP (2000) Oxidative Schädigung von Lipiden - Lipidperoxidation durch Schadstoffe. Z Umweltmed 8:160-165

33. Klaunig JE, Xu Y, Isenberg JS, et al. (1998) The role of oxidative stress in chemical carcinogenesis. Environ Health Persp 106(Suppl 1):289-295

34. Mo J, Xia Y, Wade TJ, et al. (2006) Chronic arsenic exposure and oxidative stress: OGG1 expression and arsenic exposure, nail selenium, and skin hyperkeratosis in Inner Mongolia. Environ Health Persp 114:835-841

35. Pi J, Yamauchi H, Kumagai Y, et al. (2002) Evidence for induction of oxidative stress caused by chronic exposure of Chinese residents to arsenic contained in drinking water. Environ Health Persp 110: 331-336

36. Autrup H, Daneshvar B, Dragsted LO, et al. (1999) Biomarkers for exposure to ambient air pollution comparison of carcinogen-DNA adduct levels with other exposure markers and markers for oxidative stress. Enviro Health Persp 107:233-238

37. Halliwell B (1990) How to characterize a biological antioxidant. Free Radical Res Communications 9:1-32

38. Winyard PG, Blake DR (1997) Antioxidants, redoxregulated transcription factors, and inflammation. Adv Pharmacology, San Diego, Calif 38:403-421

39. Szabo S (2000) Pathophysiological roles of nitric oxide in inflammation. In: Ignarro LJ (ed) Nitric oxide; biology and pathophysiology. Acad Press, San Diego, pp 343-354

40. Lee DH, Lim JS, Song K, et al. (2006) Graded associations of blood lead and urinary cadmium concentrations with oxidative-stress-related markers in the U.S. population: results from the third Nationa Health and Nutrition Examination Survey. Environ Health Persp 114:350-354

41. Thiele JJ, Traber MG, Packer L (1998) Depletion of human stratum corneum vitamin $\mathrm{E}$ : an early and sensitive in vivo marker of UV induced photooxidation. J Investigative Dermatol 110:756-761

42. Menzel DB (1994) The toxicity of air pollution in experimental animals and humans: the role of oxidative stress. Toxicol Letters 72:269-277

43. Bonnett R, Berenbaum M (1989) Porphyrins as photosensitizers. Ciba Foundation symposium 146:40-53; discussion 53-49

44. Fritsch C, Abels C, Goetz AE, et al. (1997) Porphyrins preferentially accumulate in a melanoma following intravenous injection of 5 -aminolevulinic acid. Biol Chem 378:51-57
45. Dissemond J, Schneider LA, Brenneisen P, et al. (2003) Protective and determining factors for the overall lipid peroxidation in ultraviolet A1-irradiated fibroblasts: in vitro and in vivo investigations. Br J Dermatol 149:341-349

46. Briviba K, Klotz LO, Sies H (1997) Toxic and signaling effects of photochemically or chemically generated singlet oxygen in biological systems. Biol Chem 378:1259-1265

47. Thiele JJ, Traber MG, Tsang K, et al. (1997) In vivo exposure to ozone depletes vitamins $\mathrm{C}$ and $\mathrm{E}$ and induces lipid peroxidation in epidermal layers of murine skin. Free Radical Biol Med 23:385-391

48. Devlin RB, McDonnell WF, Becker S, etal. (1996) Time-dependent changes of inflammatory mediators in the lungs of humans exposed to $0.4 \mathrm{ppm}$ ozone for $2 \mathrm{hr}$ : a comparison of mediators found in bronchoalveolar lavage fluid 1 and $18 \mathrm{hr}$ after exposure. Toxicol Appl Pharmacol 138:176-185

49. Montuschi P, Nightingale JA, Kharitonov SA, Barnes PJ (2002) Ozone-induced increase in exhaled 8-isoprostane in healthy subjects is resistant to inhaled budesonide. Free Radical Biol Med 33:1403-1408

50. Unfried K, Albrecht C, Klotz LO, et al. (2007) Cellular responses to nanoparticles: target structures and mechanisms. Nanotecnology 1:52-71

51. Risom L, Moller P, Loft S (2005) Oxidative stress-induced DNA damage by particulate air pollution. Mutation Res 592:119-137

52. Tanriverdi H, Evrengul H, Kuru O, et al. (2006) Cigarette smoking induced oxidative stress may impair endothelial function and coronary blood flow in angiographically normal coronary arteries. Circ J 70:593-599

53. Bernhard D, Wang XL (2007) Smoking, oxidative stress and cardiovascular diseases - do anti-oxidative therapies fail? Current Medicinal Chemistry 14:1703-1712

54. Marangon K, Herbeth B, Lecomte E, et al. (1998) Diet, antioxidant status, and smoking habits in French men. Am J Clin Nutr 67:231-239

55. Cross CE, van der Vliet A, Eiserich JP (1998) Cigarette smokers and oxidant stress: a continuing mystery. Am J Clin Nutr 67:184-185

56. Hiemstra PS (2002) The adaptive response of smokers to oxidative stress: moving from culture to tissue. Am J Resp Critical Care Med 166:635-636

57. Kanaya S, Ikeya M, Yamamoto K, et al. (2004) Comparison of an oxidative stress biomarker "urinary8hydroxy-2'-deoxyguanosine", between smokers and non-smokers. Bio Factors (Oxford, England) 22:255-258

58. Bloomer RJ, Solis AD, Fisher-Wellman KH, Smith WA (2007) Postprandial oxidative stress is exacerbated in cigarette smokers. Br J Nutr:1-6

59. Radak Z, Chung HY, Koltai E, et al. (2007) Exercise, oxidative stress and hormesis. Ageing Res Rev

60. Shing CM, Peake JM, Ahern SM, et al. (2007) The effect of consecutive days of exercise on markers of oxidative stress. Appl Physiol, Nutr Metabol/ Physiologie Appliquee, Nutrition et Metabolisme 32:677-685

61. Gomez-Cabrera MC, Martinez A, Santangelo G, et al. (2006) Oxidative stress in marathon runners: interest of antioxidant supplementation. Br J Nutr 96(Suppl 1):S31-33

62. Mastaloudis A, Leonard SW, Traber MG (2001) Oxidative stress in athletes during extreme endurance exercise. Free Radical Biol Med 31: 911-922

63. Belviranli M, Gökbel H (2006) Acute exercise induced oxidative stress and antioxidant changes. Eur J Gen Med 3:126-131
64. Machefer G, Groussard C, Rannou-Bekono F, et al. (2004) Extreme running competition decreases blood antioxidant defense capacity. J Am College Nutr 23:358-364

65. Micallef M, Lexis L, Lewandowski P (2007) Red wine consumption increases antioxidant status and decreases oxidative stress in the circulation of both young and old humans. Nutr J 6:27

66. Gorelik S, Ligumsky M, Kohen R, Kanner J (2008) A novel function of red wine polyphenols in humans: prevention of absorption of cytotoxic lipid peroxidation products. Faseb J 22:41-46

67. Pignatelli P, Ghiselli A, Buchetti B, et al. (2006) Polyphenols synergistically inhibit oxidative stress in subjects given red and white wine. Atherosclerosis 188:77-83

68. Kadiiska MB, Gladen BC, Baird DD, et al. (2005) Biomarkers of oxidative stress study Il: are oxidation products of lipids, proteins, and DNA markers of $\mathrm{CCl} 4$ poisoning? Free Radical Biol Med 38: 698-710

69. Valko M, Morris H, Cronin MT (2005) Metals, toxicity and oxidative stress. Current Medicinal Chemistry 12:1161-1208

70. Jaeschke H, Kleinwaechter C, Wendel A (1987) The role of acrolein in allyl alcohol-induced lipid peroxidation and liver cell damage in mice. Biochem Pharmacol 36:51-57

71. Jaeschke H, Knight TR, Bajt ML (2003) The role of oxidant stress and reactive nitrogen species in acetaminophen hepatotoxicity. Toxicol Letters 144:279-288

72. Mitchell JR, Jollow DJ, Potter WZ, et al. (1973) Acetaminophen-induced hepatic necrosis. IV. Protective role of glutathione. J Pharmacol Exp Ther 187:211-217

73. Bartsch H, Nair J (2004) Oxidative stress and lipid peroxidation-derived DNA-lesions in inflammation driven carcinogenesis. Cancer Detect Prev 28: 385-391

74. Gedik CM, Collins A (2005) Establishing the background level of base oxidation in human lymphocyte DNA: results of an interlaboratory validation study. Faseb J 19:82-84

75. Kasai $H$ (1997) Analysis of a form of oxidative DNA damage, 8-hydroxy-2'-deoxyguanosine, as a marker of cellular oxidative stress during carcinogenesis. Mutation Res 387:147-163

76. Palmieri B, Sblendorio V (2007) Oxidative stress tests: overview on reliability and use. Part I. Europ Rev Medical Pharmacol Sci 11:309-342

77. Palmieri B, Sblendorio V (2007) Oxidative stress detection: what for? Part II. Europ Rev Medical Pharmacol Sci 11:27-54

78. Forchhammer L, Brauner EV, Folkmann JK, et al. (2008) Variation in assessment of oxidatively damaged DNA in mononuclear blood cells by the comet assay with visual scoring. Mutagenesis 23:223-231

79. Pratico D, Lawson JA, FitzGerald GA (1995) Cyclooxygenase-dependent formation of the isoprostane, 8-epi prostaglandin F2 alpha. J Biol Chem 270:9800-9808

80. Favreau F, Petit-Paris I, Hauet T, et al. (2004) Cyclooxygenase 1-dependent production of $\mathrm{F} 2$-isoprostane and changes in redox status during warm renal ischemia-reperfusion. Free Radical Biol Med 36:1034-1042

81. Ohashi N, Yoshikawa M (2000) Rapid and sensitive quantification of 8-isoprostaglandin F2alpha in human plasma and urine by liquid chromatography-electrospray ionization mass spectrometry. J Chromatogr B Biomed Sci Appl 746:17-24 
82. Dillon SA, Lowe GM, Billington D, Rahman K (2002) Dietary supplementation with aged garlic extract reduces plasma and urine concentrations of 8-iso-prostaglandin $\mathrm{F}$ (2 alpha) in smoking and nonsmoking men and women. J Nutr 132: 168-171

83. Barden A, Zilkens RR, Croft K, etal. (2007) A reduction in alcohol consumption is associated with reduced plasma F2-isoprostanes and urinary 20HETE excretion in men. Free Radical Biol Med 42:1730-1735

84. Meagher EA, Barry OP, Burke A, etal. (1999) Alcohol-induced generation of lipid peroxidation products in humans. J Clinical Investig 104: 805-813

85. Pilz H, Oguogho A, Chehne F, etal. (2000) Quitting cigarette smoking results in a fast improvement of in vivo oxidation injury (determined via plasma, serum and urinary isoprostane). Thrombosis Res 99:209-221

86. Obata T, Tomaru K, Nagakura T, et al. (2000) Smoking and oxidant stress: assay of isoprostane in human urine by gas chromatography-mass spectrometry. J Chromatogr B Biomed Sci Appl 746:11-15

87. Montuschi P, Barnes PJ, Roberts LJ 2nd (2004) Isoprostanes: markers and mediators of oxidative stress. Faseb J 18:1791-1800

88. Yeo HC, Helbock HJ, Chyu DW, Ames BN (1994) Assay of malondialdehyde in biological fluids by gas chromatography-mass spectrometry. Analytical Biochem 220:391-396

89. Cighetti G, Debiasi S, Paroni R, Allevi P (1999) Free and total malondialdehyde assessment in biological matrices by gas chromatography-mass spectrometry: what is needed for an accurate detection. Analytical Biochem 266:222-229

90. Stocker R, Frei B (1991) Endogenous antioxidant defences in human blood plasma. In: Sies $\mathrm{H}$ (ed) Oxidative stress: oxidants and antioxidants. pp 213-243

91. Aebischer CP, Schierle J, Schuep W (1999) Simultaneous determination of retinol, tocopherols, carotene, lycopene, and xanthophylls in plasma by means of reversed-phase high-performance liquid chromatography. Meth Enzymol 299:348-362

92. Motchnik PA, Frei B, Ames BN (1994) Measurement of antioxidants in human blood plasma. Meth Enzymol 234:269-279

93. Huang D, Ou B, Prior RL (2005) The chemistry behind antioxidant capacity assays. J Agricultural Food Chem 53:1841-1856

94. Popov I, Lewin G (1999) Antioxidative homeostasis: characterization by means of chemiluminescent technique. Meth Enzymol 300:437-456

95. Sies H (2007) Total antioxidant capacity: appraisal of a concept. J Nutr 137:1493-1495

96. Briviba K, Sies H (1994) Nonenzymatic antioxidant defense systems. In: Frei B (ed) Natural antioxidants in human health and disease. Acad. Press, London, pp 107-128

97. Williams SL, Strobel NA, Lexis LA, Coombes JS (2006) Antioxidant requirements of endurance athletes: implications for health. Nutr Rev 64: 93-108

98. RKI-Kommission-Umweltmedizin (2006) Selen in der Umweltmedizin. Bundesgesundheitsbl Gesundheitsforsch Gesundheitsschutz 49:88-102

99. Siekmeier R, Steffen C, Marz W (2006) Können Antioxidanzien Atherosklerose verhindern. Bundesgesundheitsbl Gesundheitsforsch Gesundheitsschutz 49:1034-1049
100. Burns JS, Dockery DW, Neas LM, etal. (2007) Low dietary nutrient intakes and respiratory health in adolescents. Chest 132:238-245

101. Scott JA, King GL (2004) Oxidative stress and antioxidant treatment in diabetes. Ann N.Y. Acad Sci 1031:204-213

102. Urso ML, Clarkson PM (2003) Oxidative stress, exercise, and antioxidant supplementation. Toxicology 189:41-54

103. Bjelakovic G, Nikolova D, Gluud LL, et al. (2007) Mortality in randomized trials of antioxidant supplements for primary and secondary prevention: systematic review and meta-analysis. JAMA 297:842-857

104. Stanner SA, Hughes J, Kelly CN, Buttriss J (2004) A review of the epidemiological evidence for the „antioxidant hypothesis“ Public Health Nutrition 7:407-422

105. Biesalski HK, et al. (1995) Hohenheimer Konsensusgespräch: Antioxidative Vitamine in der Prävention. Dtsch Ärztebl 92:1316-1321

106. Sies H, Stahl W, Sevanian A (2005) Nutritional, dietary and postprandial oxidative stress. J Nutr 135:969-972

107. Wolters M, Hermann S, Golf S, et al. (2006) Selenium and antioxidant vitamin status of elderly German women. Eur J Clin Nutr 60:85-91

108. Kelly FJ (2003) Oxidative stress: its role in air pollution and adverse health effects. Occup Environ Med 60:612-616

109. Vinzents PS, Moller P, Sorensen M, et al. (2005) Personal exposure to ultrafine particles and oxidative DNA damage. Environ Health Persp 113:1485-1490

110. Lu CY, Ma YC, Lin JM, et al. (2007) Oxidative stress associated with indoor air pollution and sick building syndrome-related symptoms among office workers in Taiwan. Inhalation Toxicol 19:57-65

111. Maes M, Mihaylova I, De Ruyter M (2006) Lower serum zinc in Chronic Fatigue Syndrome (CFS): relationships to immune dysfunctions and relevance for the oxidative stress status in CFS. J Affective Disorders 90:141-147

112. Jammes $Y$, Steinberg JG, Mambrini O, et al. (2005) Chronic fatigue syndrome: assessment of increased oxidative stress and altered muscle excitability in response to incremental exercise. J Internal Med 257:299-310

113. Ozgocmen S, Ozyurt H, Sogut S, Akyol O (2006) Current concepts in the pathophysiology of fibromyalgia: the potential role of oxidative stress and nitric oxide. Rheumatol International 26:585-597

114. Hillert L, Kolmodin-Hedman B, Eneroth P, Arnetz BB (2001) The effect of supplementary antioxidant therapy in patients who report hypersensitivity to electricity: a randomized controlled trial. Med Gen Med 3:11

115. Poulsen HE, Prieme H, Loft S (1998) Role of oxidative DNA damage in cancer initiation and promotion. Eur J Cancer Prev 7:9-16

116. Gil L, Siems W, Mazurek B, et al. (2006) Age-associated analysis of oxidative stress parameters in human plasma and erythrocytes. Free Radical Res 40:495-505

117. Galan P, Viteri FE, Bertrais S, etal. (2005) Serum concentrations of beta-carotene, vitamins $C$ and $\mathrm{E}$, zinc and selenium are influenced by sex, age, diet, smoking status, alcohol consumption and corpulence in a general French adult population. Eur J Clin Nutr 59:1181-1190
118. Breton CV, Kile ML, Catalano PJ, et al. (2007) GSTM1 and APE1 genotypes affect arsenicinduced oxidative stress: a repeated measures study. Environ Health 6:39

119. Kelly FJ, Dunster C, Mudway I (2003) Air pollution and the elderly: oxidant/antioxidant issues worth consideration. Europ Respiratory J 40:70s-75s

120. Bundesärztekammer (2008) Richtlinie der Bundesärztekammer zur Qualitätssicherung labormedizinischer Untersuchungen. Dtsch Ärztebl 105:341-355

121. Del Rio D, Serafini M, Pellegrini N (2002) Selected methodologies to assess oxidative/antioxidant status in vivo: a critical review. Nutr Metab Cardiovasc Dis 12:343-351

122. Grune T, Berger MM (2007) Markers of oxidative stress in ICU clinical settings: present and future. Curr Opinion Clin Nutr Metabolic Care 10: 712-717

123. Voss P, Siems W (2006) Clinical oxidation parameters of aging. Free Radical Res 40:1339-1349

124. Bjelakovic G, Gluud C (2007) Surviving antioxidant supplements. J Nat Cancer Inst 99:742-743

125. RKI-Kommission-Umweltmedizin (2001) Grundsätze der Bewertung von umweltmedizinischen Methoden. Bundesgesundheitsbl Gesundheitsforsch Gesundheitsschutz 44:519-522

126. Referenzwerte (2000) Referenzwerte für die Nährstoffzufuhr. Hrsg.: DGE, ÖGE, SGE,. SVE; 1. Aufl. Umschau/Braus Verlag

127. Pryor WA (1986) Oxy-radicals and related species: their formation, lifetimes, and reactions. Ann Rev Physiology 48:657-667

128. Kelm M, Schrader J (1990) Control of coronary vascular tone by nitric oxide. Circulation Res 66:1561-1575

129. Beckman JS, Beckman TW, Chen J, et al. (1990) Apparent hydroxyl radical production by peroxynitrite: implications for endothelial injury from nitric oxide and superoxide. Proceedings of the National Academy of Sciences of the United States of America 87:1620-1624

130. Evans MD, Cooke MS, Podmore ID, et al. (1999) Discrepancies in the measurement of UVC-induced 8-oxo-2'-deoxyguanosine: implications for the analysis of oxidative DNA damage. Biochem Biophys Res Commu 259:374-378

131. Zelko IN, Mariani TJ, Folz RJ (2002) Superoxide dismutase multigene family: a comparison of the CuZn-SOD (SOD1), Mn-SOD (SOD2), and EC-SOD (SOD3) gene structures, evolution, and expression. Free Radical Biol Med 33:337-349

132. Meilhac O, Zhou M, Santanam N, Parthasarathy S (2000) Lipid peroxides induce expression of catalase in cultured vascular cells. J Lipid Res 41: 1205-1213

133. Comhair SA, Bhathena PR, Farver C, et al. (2001) Extracellular glutathione peroxidase induction in asthmatic lungs: evidence for redox regulation of expression in human airway epithelial cells. Faseb J 15:70-78

134. Nielsen F, Mikkelsen BB, Nielsen JB, et al. (1997) Plasma malondialdehyde as biomarker for oxidative stress: reference interval and effects of lifestyle factors. Clin Chem 43:1209-1214

135. Agarwal R, Chase SD (2002) Rapid, fluorimetricliquid chromatographic determination of malondialdehyde in biological samples. J Chromatography 775:121-126

136. Wong SH, Knight JA, Hopfer SM, et al. (1987) Lipoperoxides in plasma as measured by liquidchromatographic separation of malondialdehyde-thiobarbituric acid adduct. Clin Chem 33:214-220 
137. Öhrvall M, Tengblad S, Ekstrand B, et al. (1994) Malondialdehyde concentration in plasma is inversely correlated to the proportion of linoleic acid in serum lipoprotein lipids. Atherosclerosis 108:103-110

138. Hong YL, Yeh SL, Chang CY, Hu ML (2000) Total plasma malondialdehyde levels in 16 Taiwanese college students determined by various thiobarbituric acid tests and an improved high-performance liquid chromatography-based method. Clin Biochem 33:619-625

139. Fukunaga K, Yoshida M, Nakazono N (1998) A simple, rapid, highly sensitive and reproducible quantification method for plasma malondialdehyde by high-performance liquid chromatography. Biomed Chromatogr 12:300-303

140. Title LM, Cummings PM, Giddens K, et al. (2000) Effect of folic acid and antioxidant vitamins on endothelial dysfunction in patients with coronary artery disease. J Am College Cardiol 36:758-765

141. Briviba K, Schnabele K, Rechkemmer G, Bub A (2004) Supplementation of a diet low in carotenoids with tomato or carrot juice does not affect lipid peroxidation in plasma and feces of healthy men. J Nutr 134:1081-1083

142. Romero MJ, Bosch-Morell F, Romero B, et al. (1998) Serum malondialdehyde: possible use for the clinical management of chronic hepatitis C patients. Free Radical Biol Med 25:993-997

143. Volpi N, Tarugi P (1998) Improvement in the highperformance liquid chromatography malondialdehyde level determination in normal human plasma. J Chromatogr B Biomed Sci Appl 713: 433-437

144. Carbonneau MA, Peuchant E, Sess D, et al. (1991) Free and bound malondialdehyde measured as thiobarbituric acid adduct by HPLC in serum and plasma. Clin Chem 37:1423-1429

145. Suttnar J, Masova L, Dyr JE (2001) Influence of citrate and EDTA anticoagulants on plasma malondialdehyde concentrations estimated by high-performance liquid chromatography. J Chromatogr B Biomed Sci Appl 751:193-197

146. Sim AS, Salonikas C, Naidoo D, Wilcken DE (2003) Improved method for plasma malondialdehyde measurement by high-performance liquid chromatography using methyl malondialdehyde as an internal standard. J Chromatogr 785:337-344

147. Pilz J, Meineke I, Gleiter CH (2000) Measurement of free and bound malondialdehyde in plasma by high-performance liquid chromatography as the 2,4-dinitrophenylhydrazine derivative. J Chromatogr B Biomed Sci Appl 742:315-325

148. Steghens JP, van Kappel AL, Denis I, Collombel C (2001) Diaminonaphtalene, a new highly specific reagent for HPLC-UV measurement of total and free malondialdehyde in human plasma or serum. Free Radical Biol Med 31:242-249

149. Mao JM, Zhang H, Luo J, et al. (2006) New method for HPLC separation and fluorescence detection of malonaldehyde in normal human plasma. J Chromatogr 832:103-108

150. Rauli S, Puppo MD, Magni F, Kienle MG (1998) Validation of malondialdehyde and 4-hydroxy-2trans-nonenal measurement in plasma by NICl-GC-MS. J Biochemistry 123:918-923

151. Cavalca V, Cighetti G, Bamonti F, etal. (2001) Oxidative stress and homocysteine in coronary artery disease. Clin Chem 47:887-892

152. Suttnar J, Cermak J, Dyr JE (1997) Solid-phase extraction in malondialdehyde analysis. Analytical Biochem 249:20-23
153. Cighetti G, Allevi P, Anastasia L, etal. (2002) Use of methyl malondialdehyde as an internal standard for malondialdehyde detection: validation by isotope-dilution gas chromatography-mass spectrometry. Clin Chem 48:2266-2269

154. Jain SK, Krueger KS, McVie R, etal. (1998) Relationship of blood thromboxane-B2 (TxB2) with lipid peroxides and effect of vitamin $E$ and placebo supplementation on TxB2 and lipid peroxide levels in type 1 diabetic patients. Diabetes Care 21:1511-1516

155. Agarwal R (2003) Proinflammatory effects of oxidative stress in chronic kidney disease: role of additional angiotensin II blockade. Am J Physiol Renal Physiol 284:F863-F869 